\title{
Seeking the Indian Social Space
}

A Multidimensional Portrait of the Stratifications of Indian Society

Mathieu Ferry, Jules Naudet and Olivier Roueff

\section{OpenEdition}

1 Journals

\section{Electronic version}

URL: http://journals.openedition.org/samaj/4462

DOI: $10.4000 /$ samaj.4462

ISSN: 1960-6060

\section{Publisher}

Association pour la recherche sur l'Asie du Sud (ARAS)

\section{Electronic reference}

Mathieu Ferry, Jules Naudet and Olivier Roueff, « Seeking the Indian Social Space », South Asia Multidisciplinary Academic Journal [Online], Free-Standing Articles, Online since 20 February 2018, connection on 19 April 2019. URL : http://journals.openedition.org/samaj/4462 ; DOI : 10.4000/ samaj.4462

This text was automatically generated on 19 April 2019

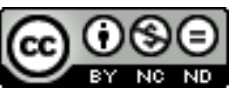

This work is licensed under a Creative Commons Attribution-NonCommercial-NoDerivatives 4.0 International License. 


\title{
Seeking the Indian Social Space
}

A Multidimensional Portrait of the Stratifications of Indian Society

\author{
Mathieu Ferry, Jules Naudet and Olivier Roueff
}

\section{AUTHOR'S NOTE}

The figures, tables and graphs in this article are best viewed in html (rather than in PDF).

The authors thank Himanshu for his help with NSSO data as well as Nicolas Robette and William Meignan for their precious help at different stages of this research. This article also benefited from presentations at OSC in Sciences Po, at LSQ-CREST in ENSAE and at the Congress of the Association Française de Sociologie.

1 This article is meant as a contribution to a sociology apprehending Indian society as a whole. It thus constitutes an attempt at countering the claim that the sociological unity of the Indian society is a myth. Supporting Aseema Sinha's call to change the scale of analysis and to stop focusing solely on the regional variations (Sinha 2015), we indeed aim at offering a synthetic map of the various forces structuring the Indian social space. Even though one cannot ignore that the unequal division of available economic, symbolic, cultural, political, and other resources is essentially carried out within the framework of a nation state, social science researchers have not yet offered a panoptic view of the Indian society as a relational space. This constitutes a serious gap in the sociological literature on India.

2 This is all the more regrettable as the theoretical and graphical representation of the social space of an entire nation state obviously constitutes an invaluable heuristic tool. There is no doubt that, in spite of all its weaknesses, the central figure of Bourdieu's Distinction on which he maps the relationship between social stratification and taste has enduringly transformed the way many sociologists read society (Coulangeon et Duval 2013: introduction). Offering a panoptic view of a society while simultaneously unveiling the structuring principles of the relations between these groups constitutes an invaluable resource for all the social scientists who attempt at "locating" or "contextualizing" their research within a larger frame. One of Bourdieu's main contributions indeed lies in the 
relational perspective of his approach: to be located in a social space amounts at being located in it in regards to other individuals or to other social groups. Therefore no aspect of a society can be seriously studied without understanding its relationship with the other components of this given society.

This article takes as its specific starting point the idea that the Indian society constitutes a relational space, marked by the interdependency of various sub-spaces. ${ }^{1}$ We indeed consider that the fragmentation of the Indian polity into several States is in itself a form of integration that makes it possible to forge the coherence of the whole (Stepan, Linz and Yadav 2010). Although the different States enjoy a certain autonomy, they are not completely free of their neighbors and are hence caught up in extremely restrictive relationships of interdependency. The form of the nation state thus forces the sociologist to consider the Indian social space in its entirety, even if it is undoubtedly split into subspaces that obey distinct rationales. Following this basic assumption, the aim of this paper is to produce a sociologically coherent image of Indian society. ${ }^{2}$

Two points deserve to be underscored at this point. The first is that there is almost no statistical representation of the stratifications of the Indian society based on a multidimensional approach-that is to say one that simultaneously takes a large quantity of social properties into account and goes beyond the caste/class debate, which we will return to below. As in many countries, the national statistical scale in India is monopolized by economists and development specialists, and thus focuses mainly on questions of inequality in purchasing power or healthcare. So much so that the "macro" nature of our analysis that aims to characterize a social structure consisting of 1.2 billion people on the basis of 51 statistical indicators, could seem both too crude and too obvious. Too crude for the advocates of qualitative methods, by far the dominant group within the Indian social sciences, and too obvious for specialists of statistical studies from elsewhere, who may consider our approach, at best, a first, elementary step before moving on to more innovative interrogations. Now it is precisely this first, decisive step that is lacking in the case of India and we intend to fill this gap by constructing it in the most substantial manner possible: although based on pioneering works that we will return to below, the statistical cartography of the Indian social space provided at the end of this article is unprecedented.

Secondly, the debates on the transferability of concepts, nomenclatures and methodologies developed by and for Western nation states in the rest of the world are legion (Lardinois 2013). In this respect our approach is resolutely pragmatic. Convinced that the devil does not lie in the statistical approach itself, but in the modalities of its application, we will create our indicators as reflexively and explicitly as possible, on the basis of available data, and we will use a geometric data analysis, which is relatively inductive. While the choice of the variables before they are introduced into the calculation is decisive, no hypothesis regarding their relative weight and their statistical relationships is suggested a priori (for example on the importance of caste versus class) (Le Roux and Rouanet 2004). ${ }^{3}$ In the end, the potential utility of the approach lies more in the results than in its underlying principles: have we learnt something about Indian society? Would other principles allow us to learn something more?

6 In order to achieve the objective of producing a synthetic representation of the Indian social space, the analysis proposed in this paper is carried out in three stages. In a first section, we explore four arguments in favor of the thesis of India's unity. In a second section, we attempt to discuss the methodological means employed to apprehend the 
Indian social space. We specifically justify our choice to use factor analysis and to base our analysis on the 2011-2012 data from the "consumption" section of the National Sample Survey. Then in a third section we examine the data. To start with, we interpret the factors that structure the dispersion of individuals or variables along the first two axes of the factor analysis. Then on the basis of an Ascending hierarchical classification (AHC), we attempt to produce a typology of consumption and position profiles around which the people who make up the Indian social space are aggregated. This work leads us to suggest a summary figure of the principles that organize the Indian social space and the nine categories that comprise it. The most technical aspects of our methodology and of our analysis are presented in two separate appendices (Appendix 1, Appendix 2).

\section{Arguments in favor of a unified approach to the Indian social space}

7 Before carrying out our relational analysis of the Indian social space, we would like to briefly introduce the reasons that substantiate our choice of a unified approach to the Indian society. Though there exist solid reasons in favor of the argument of the irreducible fragmentation of the Indian society, it indeed seems to us that the opposite thesis of a unified society has not been sufficiently investigated, except by Louis Dumont, whose approach remains fundamentally idealistic. Choosing a more materialistic approach, we more specifically base our study on four arguments that support a unified approach to the Indian social space.

The first argument acknowledges the mobility that occurs at a pan-Indian scale. The existence of extreme mobility trajectories is, in fact, sufficient reminder that although the social space of a village in Bihar does not follow the same rationales as the social space in Delhi, the educational success of some (Naudet 2012), or migration linked to daily labor for others (Dupont 2013), creates indisputable links between these two spaces. In addition, it is not by chance that the most encompassing and synthetic approaches to the Indian social space are found among sociologists of social mobility. Their object of study effectively forces them to conceptualize the social space as a whole. Following on from the work by Bam Dev Sharda (1977), Edwin and Aloo Driver (1987) and many others, Sanjay Kumar, Anthony Heath and Oliver Heath (2002) as well as Divya Vaid's work represents another crucial step forward (Vaid 2012; Vaid and Heath 2010). In order to measure movement between social classes, these works are based on a schema of five main classes that allow us to apprehend Indian society as a whole.

The second argument that pleads in favor of a unified approach to Indian society is the erosion of the opposition between rural and urban Indian. Although the 2011 Census shows that nearly three out of four Indians still live in a rural area, and that 58 percent of the active population is still working in the agrarian sector, the frontier between these two types of spaces is increasingly blurred. The concept of "subaltern urbanization" (Denis, Mukhopadhyay and Zérah 2012) perfectly sums up this evolution of Indian society. In India now, there are many spaces that are urbanized areas, despite the fact that they were not originally planned urban centers and are not recognized by the Census of India as urban territories. This phenomenon of new urbanization and the growing space occupied by "small towns", inhabited by an ever-increasing share of the population, are reminders that the urban and the rural should not be considered as unique and distinct 
but, on the contrary, should be looked at in combination. The official categories employed by the Census of India are hence, in this respect, insufficient and it is reductive to contrast two distinct social spaces solely on this basis.

However, the majority of sociologists continue today to approach urban and rural spaces separately, sometimes going as far as creating a different class schema for each space. By doing this they reinforce the idea that these spaces are different in "nature", and function according to unique and distinct rationales. It is hence urgent to forge conceptual tools capable of explaining the changes taking place in Indian society. It is this that Surinder Jodhka (2014) exhorts us to do when he recalls that numerous villages-still counted as such by the Census of India-have evolved into small towns where the inhabitants' lifestyles and consumer practices are undergoing dramatic changes. Today these spaces would include over half the inhabitants of the so-called "rural" zones.

11 To relativize the frontier between the rural and the urban in this manner, is in no way an attempt to dissolve it completely: the social configurations of a small agricultural village, a medium size town of several hundred thousand inhabitants and a megapolis, still remain vastly different. What is called into question is the binary division, at the empirical level, between the rural and the urban against a backdrop of continuity and relative empirical diversity that runs from the little village to the vast megapolis. At the theoretical level, what is challenged is the essentialization of this rupture, to the extent that it would seem that each category requires a corresponding framework of analysis.

The third argument in favor of a unified approach to Indian society is the country's economic unity. Echoing (yet standing apart from) the debates on the cleavage between urban and rural India, there is a trend of thought both in academic circles as well as in the media that affirms the existence of two distinct "Indias": that of the middle classes who are integrated into the dynamics of globalization, and the marginalized India of the poor masses. This trend of thought consists in stating, more or less theoretically, that two social spaces coexist within a single society, and that they function according to completely disjointed rationales. In terms of prenotions, this idea is most often embodied -emblematically so-in the expression "the other half" or in the recurrent usage of the title "A tale of two Indias" (just typing the name into a search engine clearly shows the high number of articles with titles inspired by Dickens' eponymous novel).

From an academic perspective, this conception of a social space irremediably disassociated into two distinct subgroups appears in several avatars. The most frequent opposition is between the formal and the informal economies, contrasting regular financial transactions with a subterranean economy beyond the purview of the State authorities (Chaudhuri, Schneider and Chattopadhyay 2006). Others recall the existence in India of two distinct goods markets, as the Indian government buys wheat, rice and sugar at prices lower than market price to distribute these products through "ration shops" (Schiff 1994), which would contribute to destroying market unity.

14 Numerous economists also point to the existence of a two-tier economy, which, in particular, leads to the emergence of a two-tier labor market. The question of workers' legal statuses effectively constitutes a privileged argument when considering the existence of "two Indias". Barbara Harriss-White (2003) has thus drawn attention to the importance of the divide between organized work (that is to say work controlled by the regulations of the Indian labor code, which provides legal protection for workers) and unorganized work (that is to say work undeclared under the Factories Act and not regulated by any State law), with the latter involving between 40 to 85 percent of the 
country's active population, according to the estimates (Harriss-White 2004). The demographer Vijay Joshi (2010) specifically points to the fact that the alarming unemployment rate, despite high growth, may well reinforce the existence of a two-tier economy, in which a first dynamic would benefit from liberalization and globalization, but would only employ a minority of the population, while a second movement would contribute to reinforcing an informal economy that would ensure the subsistence of the poorest masses.

It is impossible not to acknowledge these types of huge gaps between living and working conditions in Indian society-and the consumption analysis we present provides further proof, if it were required. But nonetheless, is it justified to deduce that these gaps determine incommensurable social worlds, in the true sense of the term, and that they hence have heterogeneous structuring principles requiring different frames of analysis? Our hypothesis posits that, on the contrary, these gaps develop out of common scales of distribution of resources and statuses.

Lastly, a fourth element allows us to highlight the urgency of developing a unified approach to Indian society. This is the growing obsession with the middle classes. While these so-called "middle" classes were almost absent from Indian historiography (which focused more on the peasantry and the dominated or subaltern classes) for a long time, since the wave of accelerated liberalization that occurred from 1991 onwards, they have been central to all the debates on the transformations affecting India. One can but recognize that this recent interest is more the object of ideological speculation (Varma 1998) than empirical analyses, with a few exceptions among which we can mention the works by E. Sridharan (2004), Leela Fernandes (2006) or Satish Deshpande (2006). Attempts to define this group often remain limited, and the middle classes are very commonly reduced to their urban location. They are also often assimilated to the upper classes, with middle class often serving as a reference to the idea of the middle bourgeoisie in English speaking countries (and upper class to the idea of the upper bourgeoisie). As a result, the definitions generally emphasize their purchasing power, suggesting by this that these social groups are primarily understood through the lens of the marketing target they represent in a context of high economic growth (Jodhka and Prakash 2016).

Numerous researchers have thus attempted to define the middle class on the basis of its income or its levels of consumption, according to constantly shifting criteria. ${ }^{4}$ The primacy of an approach based on purchasing power, however, contributes to maintaining the confusion between the dominant classes and the middle classes, and neglects a more sociological definition of social classes. Consumption is not only an economic activity to be measured by specific monetary amounts: it also refers to "lifestyles" characterized by different choices in the manner of spending a same sum of money.

It is also dangerous to assimilate groups endowed with strong decision-making power to others that occupy intermediate positions and only have limited-and controlled-access to mass consumption. Are senior executives with high purchasing power or long-armed senior civil servants truly representative of a middle class? Given the decision-making power they enjoy, should we not situate them instead within the dominant class (in Bourdieu's sense)? If the answer to this question is positive, then the Indian middle classes are not what they were long thought to be.

One must also remember that certain senior civil servants may enjoy socially dominant positions without necessarily possessing high purchasing power. As Mazzarella (2005) 
recalls, the idea of middle class in India also refers to a bureaucracy that inherited the legacy of the Nehruvian era that leaves them "short on money but long on institutional perks". It is hence important not to focus solely on consumption and it is imperative to couple this with other social indicators (social class, place of residence, level of qualification, profession, etc.).

In addition, there is a whole range of groups that Indian sociology has ignored for too long, which lie between the country's dominant classes and the most subaltern groups, whose existence is worth mentioning. The definitions of the middle classes mentioned above indeed tend to amalgamate people from very diverse social situations and with highly contrasting lifestyles. What does an executive working for a multinational, who has a degree from the East Coast of America, lives in a luxurious condominium in Gurgaon, enjoys the comforts of domestic staff at home, dines regularly at five star hotels, and travels abroad every now and then, have in common with an automobile showroom salesman, who has a degree in commerce from a small university in Uttar Pradesh and lives in a small room in an urban village that he shares with two colleagues? Certainly very little. While the latter is closest to the masses that make up the Indian middle classes, as they are defined in many of the works cited above, it nonetheless remains the former who best corresponds to the stereotyped portrait of the middle classes that most of the media draw upon. An encompassing approach to the Indian social space undoubtedly constitutes the only means of arriving at a rigorous and clear definition of the middle classes. And it is only such an approach that will allow us to consider the connections between these fractions of classes, including the upper classes as well as the most subaltern groups.

These four arguments in favor of a unified approach to Indian society thus lead us to suggest a quantitative approach to the Indian social space. This offers an overall view of the principles that structure the relationships between the social groups that compose it. In our opinion, this requires a perspective that is both multidimensional and relational, which a geometric data analysis can provide (Le Roux and Rouanet 2004). It effectively allows one to study the distribution of consumer practices, both in comparison to each other and in relation to the distribution of social properties, within one single statistical calculation (and not studying one or two practices at a time, or one or two properties at a time). Treating all the variables selected and their interactions simultaneously, moreover allows the plurality of the principles that structure the distribution of practices to emerge inductively: the social space obtained is multidimensional, organized according to several factors, each one correlated to one or several variables that are to be interpreted.

\section{Questions of method}

The analysis presented here is based on the survey "Household Consumer Expenditure" conducted by the National Sample Survey Office (NSSO) 2011-2012 ( $68^{\text {th }}$ round), involving 101,662 households that are representative of the Indian population $(1,210,193,000$ inhabitants in 2011). This survey is conducted using questionnaires. The surveyors ask questions regarding household consumption on no less than 273 different items of consumption, and they collect both expenditure and quantities. The consumption reference period is 7 or 30 days for daily consumer goods and 365 days for durable goods. Whenever possible we focused on the thirty-day reference period, the method usually preferred in Indian surveys (Deaton 2003). 
NSO household consumer surveys show high divergences (of about 50 percent) from the National Accounts Statistics of India (NAS), which corresponds to the national accounting reports. These variances are due to the different means by which the surveys are conducted, something we also find in other developing countries (Deaton 2001). Two of these variances deserve to be mentioned here as they underscore the difficulty of conducting statistical surveys on Indian society. To start with, surveyors have more difficulty accessing the richest households, mainly because they tend to reside in isolated private neighborhoods. Then, the collection method does not differentiate non-responses from a lack of consumption (level 0). Now, non-responses are more likely to concern the richest households, which can create distortions that are difficult to rectify.

asets are generally mainly mobilized by economists in order to calculate poverty thresholds on the basis of overall consumer levels (Deaton 2003; Rangarajan and Sharma 2014) or in order to measure global levels of inequality (Himanshu 2015). Contrarily to such economic studies, our paper aims at revealing the disparities in the composition of consumer baskets and this is why we thus favor an analysis of household budgets drawing upon geometric data analysis. ${ }^{5}$ We are indeed as interested in styles of consumption as in levels of consumption. We thus chose to develop an approach that is as inductive as possible. Our analysis can more precisely be broken down into five steps that progressively reveal the consumption structure of Indian households, which are presented in detail in Appendix 1 (data and methods) and in Appendix 2 ("zooms").

The first step consisted in selecting 37 detailed and aggregated ${ }^{6}$ budgetary items in order to calculate budgetary coefficients for each household. This selection is based on budgetary items that allow us to highlight disparities in consumption, while maintaining the sociological coherence of the selected basket. The selected items end up representing close to 86 percent of the average total budget of Indian households. Durable goods are included in the analysis on the basis of possession (household appliances and means of transport). In a second step, we selected 14 social position variables that allow us to grasp different segmentations of Indian society, mainly the level of consumption, the living environment (urban or rural, and geographic ${ }^{7}$ ), caste, religion and social class (see Appendix 1 for a detailed presentation of the active and supplementary variables used in this study).

In a third step, we produced a Principal Component Analysis (PCA) that permits a graphic representation, on two-dimensional planes, of the correlations measured between the budget variables (active variables), while seeking associations with social position variables (supplementary variables). This offers a first representation of Indian social space, of which the main factors (or "structuring principles") are disparities of wealth and geographical variations (see Appendix 1 for further details). ${ }^{8}$ It is particularly interesting to remark that the "States" variable is the most highly correlated, by far, on the first plane. In other words the "State" variable "explains" a large share of the correlations observed, as one can see by looking at the projection of State variables on factorial plans 1 and 2 (Figure 1). 
Figure 1 - Unstandardized Factor analysis (PCA) of the Indian social space. Plane 1-2

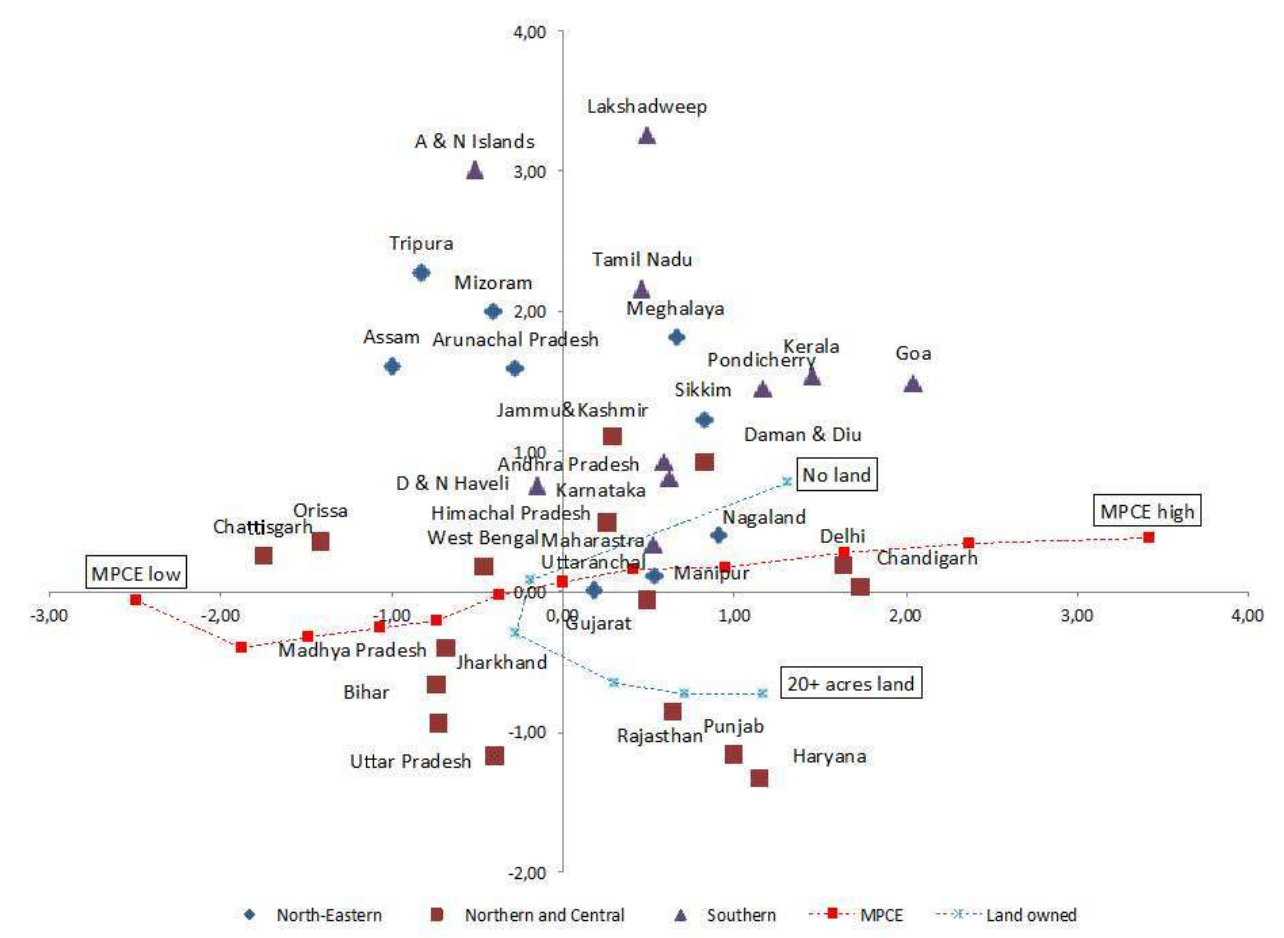

NOTE: THE REPRESENTATION OF PLANES 1-2 SHOWS THREE COHERENT gEOgRAPHICAL gROUPS. AXIS 1 IS CORRELATED WITH THE STANDARD OF LIVINg (MPCE) WHEREAS AXIS 2 IS CORRELATED WITH OWNERSHIP OF LAND.

Data: Consumer Expenditure Survey, National Sample Survey 68 ${ }^{\text {th }}$ Round (2011-2012)

The projection of the "State" variable on the first and second axes of the PCA indeed reveals three coherent groups: the states of the north and the center (at the bottom of the figure, and spread along the first axis), associated with the possession of large landed property, the states of the south (at the top right of the figure) and the states of the north-east (spread along a diagonal going from the top left of the figure towards the bottom right). The weight of regional disparities is hence a determining factor in the explanation of modes of consumption.

These three geographical clusters correspond to the well-documented divide between regions on the basis of language (respectively Indo-European, Dravidian and TibetoBurman), economics, culture and climate. But the identification of a geographical effect is not really heuristic as such. The consumption of certain food goods may be linked to the geographical location of the respondent, which is itself dependent on climatic conditions, or linked to price variations between consumer goods, depending on the State. The geographical variable may also conceal other effects that structure the social space, such as standards of living, the caste system, or urbanization. In this latter hypothesis, the geographical structure actually masks the social structure that we seek to reveal. In order to avoid such an unfortunate bias, the fourth step of our analysis thus consists in neutralizing the "State" variable in order to recalculate correlations "free" of this geographical effect. ${ }^{\text {" }}$

29 To do this we use the Standardized factor analysis method (SFA) that neutralizes the effect of a variable on the construction of the factor axes of a geometric analysis, in order to study structural effects (Bry, Robette and Roueff 2015). In metaphorical words (see 
Appendix 1 for a detailed presentation), this algorithm acts as if one had forced all modalities of the "State" variable to be located at the crossing of the axes of our twoplanes figures (i.e., the coordinates " 0,0 "), just as if its effect were null. It then reorganizes all other data (the points representing each individual as well as each category of active and supplementary variables except "State") depending on this constraint. This manner of neutralizing one of the main indicator of heterogeneity in the Indian social space (variations by State) directly illustrates the pragmatic nature of our approach: it does not intend to demonstrate the unity of the Indian social space at the national scale (not finding the variations we have neutralized can obviously not constitute an empirical proof of unity!) but it's rather focused on figuring out what kind of knowledge can be produced by carrying out an inductive analysis based on the hypothesis of unity. The analysis of the key polarizing factors of this Standardized PCA (to which we will refer as "SFA") is presented in this article.

In the same rationale, we also analyzed the structural effects revealed by "zooming" our SFA on subsamples, in order to compare the pan-Indian social space with rural and urban spaces, and richest, intermediate, and poorest households' spaces. The main result is that each of these spaces is very similar to the others-even if some minor variations are very heuristic (see Appendix 2 for details and results). This methodological detour helped us be confident in the statistical validity of the standardized factor space.

31 The last step of our analysis finally consisted in developing a synthetic description of the fractions of the Indian social space by conducting an Ascending Hierarchical Classification (AHC), based on the previous standardized factor step. This AHC allows us to construct a rich typology of the Indian social space that distinguishes nine fractions of classes with contrasting consumer profiles. Rather than corresponding to a mere scale of economic capital, each of them corresponds to a combination of social properties (total level of consumption, as well as the area they live in, caste, qualification and property ownership). This allows us to construct a statistically substantiated representation of the Indian social space. The discussion of this representation actually constitutes the core of this article.

\section{Structuring principles and fractions of the Indian social space}

\section{The weight of need: the structuring principles of the Indian social space}

Having statistically neutralized the effect of regional variations, our analysis consists in drawing upon the SFA (see figure 2 below) in order to explore the key polarizing factors in Indian society. The statistical method adopted allows us to reveal the massive weight of the level of wealth and the specific effects of secondary principles such as caste or living in a rural or an urban area. The overall outcome of the standardized factor analysis is unambiguous. The distribution of consumption follows two correlated but distinct rationales (figure 2, also see Appendix 1 for a detailed presentation of the contribution of active and supplementary variables). 
Figure 2 - Pan-Indian Standardized factor analysis. Plane 1-2

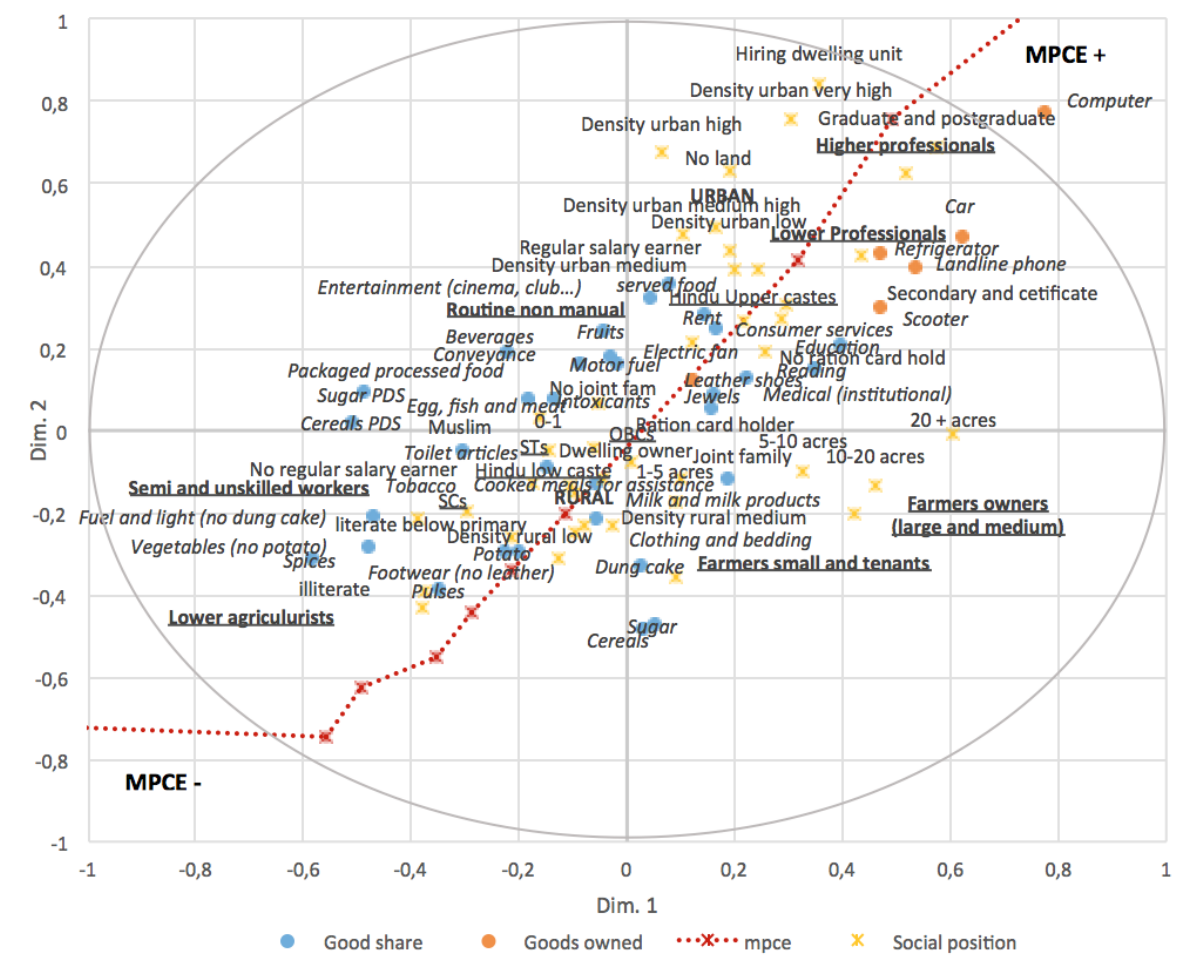

NOTE: IN RED, THE CONSUMPTION LEVEL; YELLOW CROSSES: THE OTHER POSITION VARIABLES (SPECIfiCALlY: LEVEL OF EDUCATION, PROFESSIONAL CATEgORY, RELIgION, SCHEDULED CASTE, DEMOgRAPHIC DENSITY, LAND OWNERSHIP, AREA OF RESIDENCE); IN BLUE: PROPORTION OF THE BUDgET DEDICATED TO EACH gOOD; ORANGE DOTS: THE LEVEL OF EXPENDITURE FOR EACH gOOD.

DATA: CONSUMER EXPENDITURE SURVEY, NATIONAL SAMPLE SURVEY 68TH ROUND (2011-2012)

On axis 1 (horizontal), most of the goods owned (orange dots) are located on the right and most of the budgetary coefficients (blue dots) are located on the left. This axis thus sums up an opposition between budgetary structures in which a large share is reserved for subsistence goods (food, in particular, but also basic energy, basic clothing) and budgetary structures in which a large share is dedicated to comfort goods (computer, refrigerator, land line telephones, air conditioning and fan, expenditure on education, leisure, transportation, etc.).

As for axis 2, it shows consumption structures related to rural lifestyles (at the bottom) and consumption structures associated with urban lifestyles (at the top). Thus in subsistence consumption, a rural variation (dung cake, ${ }^{10}$ non-subsidized sugar and cereals) can be distinguished from an urban variation (other energy sources, subsidized sugar and cereals $\left.{ }^{11}\right)$. Similarly, some comfort consumption categories are more urban (commercial leisure activities, packaged drinks, served meals, fruits) - but few seem to be specifically rural.

This interpretation is confirmed when we observe the variables of social position projected onto the same space as supplementary variables.

Axis 1 (horizontal) is very clearly principally associated with social position variables: the level of consumption, the professional category, the level of education and caste, with the social scale "rising" from left to right. More precisely, on the right we find farmer 
owners, higher and lower professionals, and on the left, subaltern agricultural and industrial workers. Axis 2 (vertical) contrasts a more urban world of work (higher and lower professionals) with a more rural working universe (farmers, subaltern agricultural and industrial workers).

Finally, the diagonal along which the consumption variables, and moreover, the social position variables are aligned, express the structuring power of the level of consumption (Monthly Per Capita Expenditure or MPCE), associated with the level of education and caste, and secondarily with the sector of residence-although the latter has a specific weight, it is nonetheless clear that the rich are more commonly found in cities. It is also to be noticed that the results obtained after zooming on subsamples distinguishing respondents living in rural and urban environments, or the richest, intermediate and poorest households, further show that these different sub-spaces are overall very similar to each other and to the global space (see Appendix 2 for a detailed analysis of the minor but nonetheless heuristic differences that appear on these subspaces).

The SFA shows different position variables-professional category, caste, level of education-aligned with the level of consumption (see Figure 2). From this, one could deduce that the latter is a sufficient indicator of the social position or, in other words, that the social scale can be reduced to an opposition between rich and poor. Now, as suggested above, this is not the case: the different position variables are certainly correlated, but not strictly redundant. The case of caste is a good illustration of this. ${ }^{12}$

On the one hand, caste is strongly associated with the professional category. The scheduled tribes (STs) and scheduled castes (SCs) are over-represented among the daily agricultural workers and the unqualified or little qualified workers, while the upper castes are very highly over-represented among the higher and lower professionals. The $\mathrm{OBCs}$ are, for their part, represented in a relatively balanced manner over all the professional categories, although they are under-represented among the higher categories but over-represented among petty shopkeepers. On the other hand, a closer look at what is happening at the "top" and the "bottom" of the social space shows that a linear association between caste and class is not necessarily the rule (see Appendix 2 for further details). A zoom on the sub-space of the poorest indeed show that the small differences between the poor are more strongly based on caste than on education or the professional category. Among the populations that possess no economic or cultural capital, the caste one belongs to would hence make an enormous difference in terms of creating a minimum distance from the weight of need, much more so than social class or education.

This last remark encourages us to take into account the secondary differentiating factors that "complicate" the massive effect of the level of consumption. Beyond an arbitrary division into two (a two-tier India) or three (the classic upper, middle and lower classes), is it possible to distinguish a typology of the Indian social space that simultaneously reveals the dizzying length of the social scale, its twists dependent on the combination of varying social power relationships (wealth, profession, education, caste) and the multiplicity of its successive levels? The production of an ascending hierarchical classification on the standardized PCA turns out to be particularly convincing in order to further explore the multidimensionality of the Indian social space. 


\section{The nine categories of the Indian social space}

41

As we've seen, the exploration of the structuring principles of the Indian social space leads us to note an interaction between the massive weight of economic capital and the secondary effects of other power relationships like the level of education, professional category, caste and the rate of urbanization. To study this interaction further, we use an Ascending Hierarchical Classification (AHC) carried out on the "standardized" space of consumption. By segmenting the population on the basis of the relative commonality of the same consumer practices, we expect to obtain groups that have sociologically coherent social properties. The statistics of the semi-partial $R$ squared show thresholds at 3 , 7 and 9 clusters. The segmentation into 3 is rejected as one of the clusters groups 95 percent of the sample. The segmentation into 7 is more relevant, but has the drawback of combining two diametrically opposed sociological profiles-the richest and the mass of popular classes-within the most numerically important cluster (48.3 percent of the sample). The classification combines them as they share a higher rate of non-responses. In fact, the segmentation into 9 separates these two profiles into two distinct clusters.

cluster analysis is based on the modalities of the consumption and position variables that are over and under-represented within each cluster. We thus obtain the most typical modalities of each cluster. It is all the more necessary to take the precautions usually applicable to any classification, as the inevitable statistical "noise"-that is to say the people in the sample whose qualities are badly captured by the segmentation-are incorporated into the clusters here. Such classifications often produce a larger or smaller cluster, which condenses the main residues that cannot be reduced to any factor of classification. Here, this cluster, the $9^{\text {th }}$, turns out to be very small $(0.69$ percent of the sample) and, moreover, it is relatively interpretable (we will return to this). In contrast, each of the other clusters shows a sociologically coherent majority profile while also remaining relatively heterogeneous: each cluster consists of a non-negligible proportion of aberrant individuals from the viewpoint of the dominant profile they appear alongside. Thus the segmentation we present should not be read as a strict representation of the classes and fractions of classes that make up the Indian social space. It is a typology of polarities that structure this space: the consumption and position profiles around which cohesive circles of individuals aggregate are surrounded by wide, less homogenous fringes with borders that overlap between profiles. It is this polarized rather than segmented social space that Figure 4 (see below) attempts to represent in a synthetic manner, the percentage size of each cluster being more an indication of the relative importance of each profile rather than an accurate quantification of a social group.

The MPCE variable that contributes the most to the construction of the space clearly organizes the nine clusters. Figure 3 also shows that the relative dispersion of each cluster around the medians (bold lines separating the white rectangles from the second and third quartiles) reduces linearly with the level of expenditure, with the exception of cluster 5 , which we will return to below. The size of the third quartiles (upper white rectangles), the position of the averages (diamonds) and the position of the extreme individuals in the fourth quartiles (stacking of bold dots at the apex of the graph) show that this heterogeneity is mainly due to the relative presence of very high levels of expenditure within each cluster.

South Asia Multidisciplinary Academic Journal , Free-Standing Articles 
Figure 3 - Box plots of the levels of consumption for the nine clusters of the social space

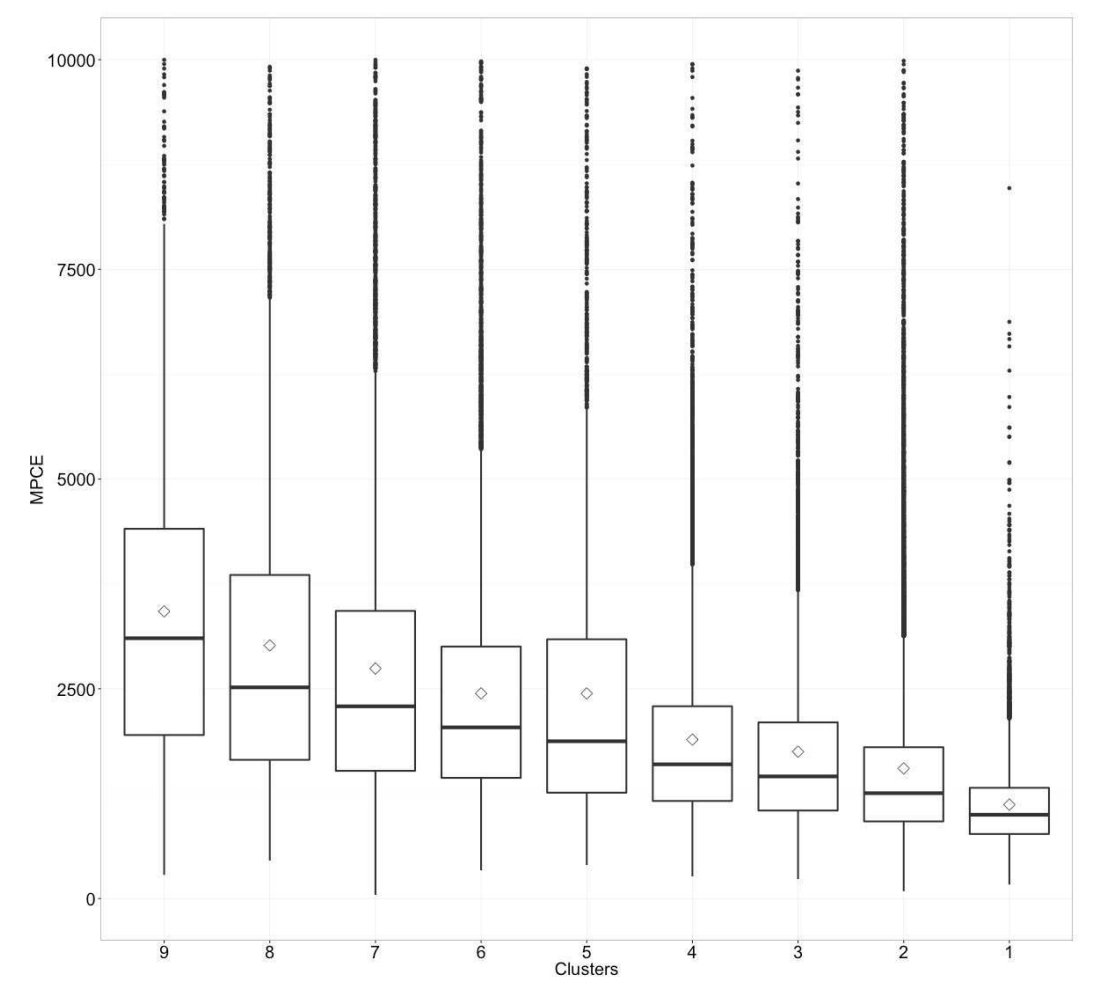

NOTE: EACH BOX PLOT SHOWS THE MEDIAN OF THE DISTRIBUTION OF CONSUMPTION (BOLD HORIZONTAL LINE), SURROUNDED BY THE SECOND QUARTILE (BELOW) AND THE THIRD QUARTILE (ABOVE).

DATA: CONSUMER EXPENDITURE SURVEY, NATIONAL SAMPLE SURVEY 68TH ROUND (2011-2012)

44 This arrangement by level of consumption (Table 1) reveals three groups: 3 fractions of the popular classes (clusters 1, 2 and 3), 2 fractions of the intermediate classes (clusters 4 and 5) and 3 fractions of the affluent classes (clusters 6, 7 and 8) to which we will add the upper class profile of cluster 9. 
Table 1 - Synthetic summary of the clusters in the Indian social space

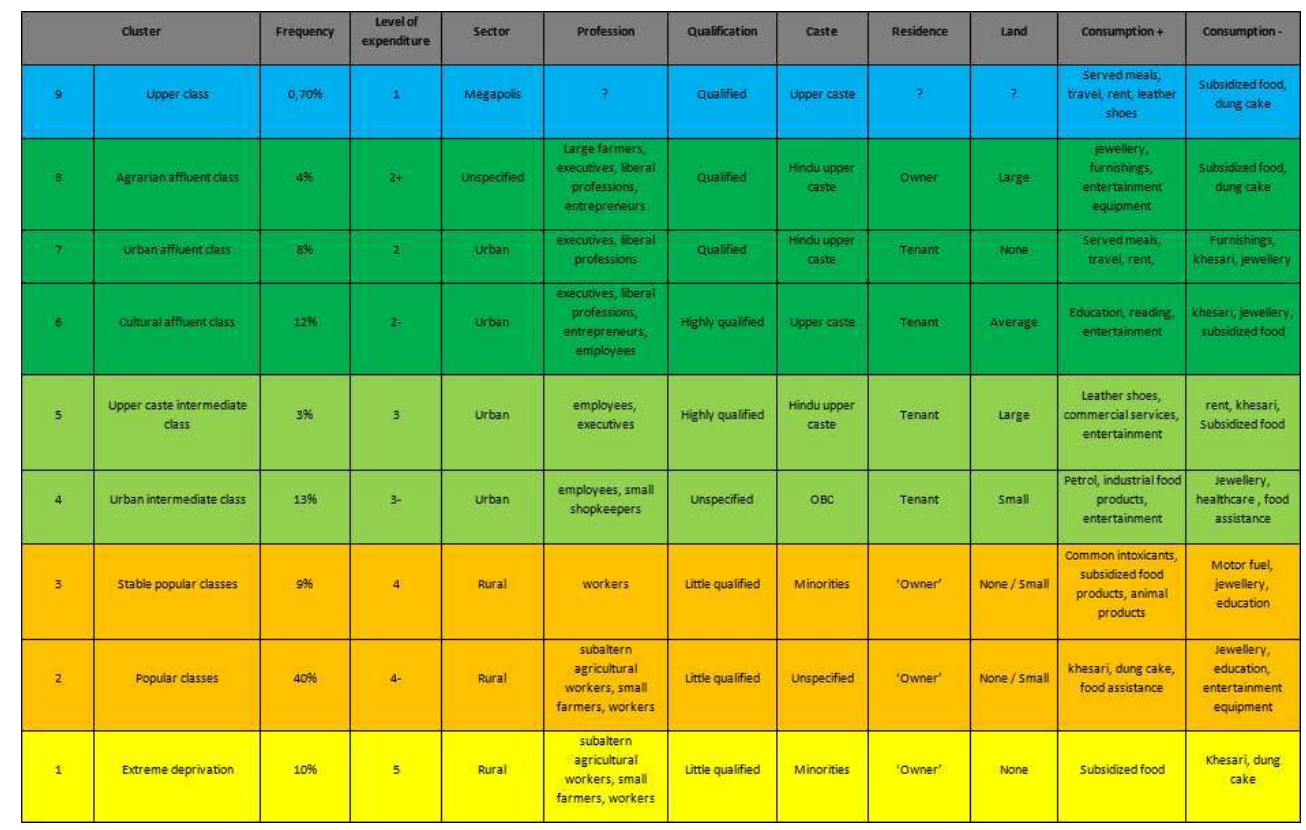

Figure 4 - Synthetic diagram of the Indian social space

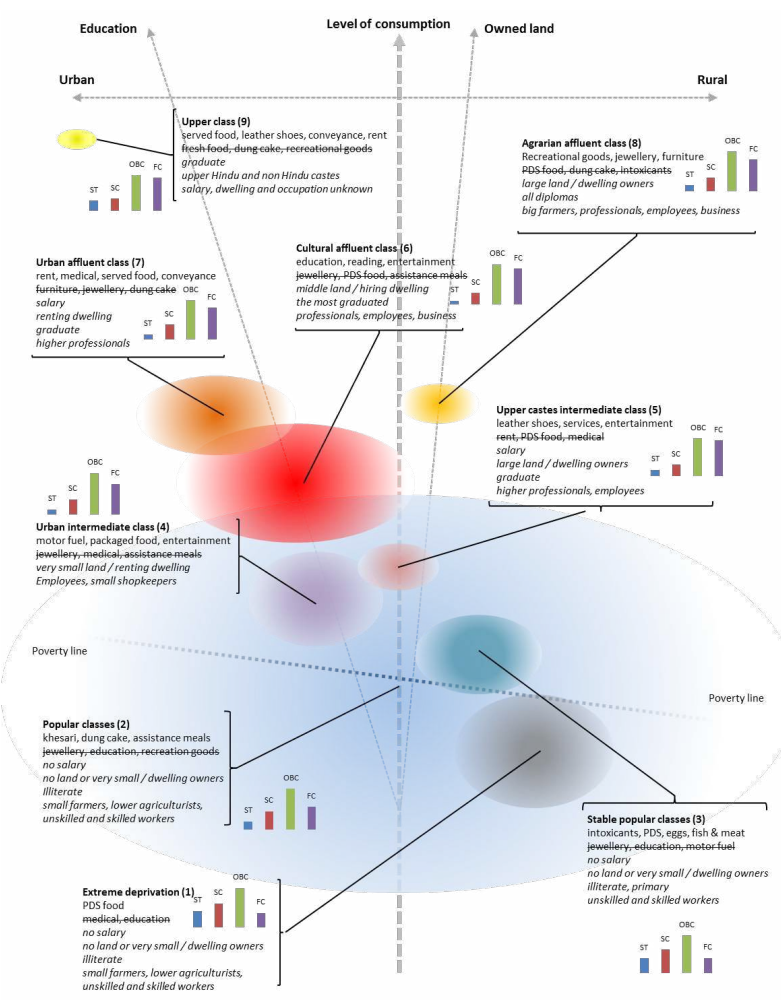

Legend: The clusters are positioned on the vertical scale of the level of consumption (MPCE) depending on their median, and on the horizontal rural/urban axis according to the share of urban and rural. Their width corresponds to the percentage of the sample represented by each of them (the height is merely half the width). The vignettes show the name of the cluster and its number in brackets, the under-represented modalities with a strikethrough, the over-represented social position in italics, the distribution of reserved groups (castes) - scheduled tribes (ST), scheduled castes (SC), other backward classes (OBC), forward castes (FC). 


\section{The popular classes: 59 percent of the Indian population} resources among the poorest, which we had already noticed thanks to the PCA: caste status and network and/or relative job stability enable the individual to escape at least the most extreme deprivation. Indeed, cluster 2 , the largest with 40 percent of the population, embodies the most common profile in India, that of severe poverty (the second lowest level of expenditure) in rural and suburban zones. The modal consumption is marked by constraints, although it escapes the most extreme need: it is defined, in a way, in opposition to rich and urban consumption (under-representation of expenditure on leisure and education as well as jewelry) as well as to the most deprived level of consumption (access to khesari, dung cake, food and basic footwear, under-representation of subsidized food products). With 40 percent of the population, the spectrum of social properties is relatively wide. It is nonetheless clearly located "below" the better endowed groups in the social space and just "above" the most deprived: it is characterized by illiterate and low-level qualifications, agricultural workers and small farmers, workers and unqualified employees, as well as owners of land of all sizes (an agricultural holding may be large but infertile) and owners of their homes. Members of all religions and castes belong to this cluster, but forward Hindu castes are underrepresented whereas OBCs are slightly overrepresented.

Stable popular classes. Cluster 3 is relatively poor but escapes the most compelling need. With 9 percent of the population, it is concentrated around subsistence consumption, including subsidized food, as well as small comfort expenditure-particularly everyday intoxicants (tobacco, betel, etc.), spices, animal food products. In terms of social properties, it is difficult to distinguish it clearly from cluster 2. But as Cluster 3 is associated with average density areas, we interpret it as a fraction of the popular classes who have achieved stability through access to small resources and jobs in areas of subaltern urbanization.

As the positioning of the poverty threshold in Figure 4 shows, the three profiles described above: extreme deprivation, severe ordinary poverty and stabilized positions in the popular classes, in themselves justify the utility of a multidimensional approach. Focusing only on the economic threshold of poverty and the debates on the methods used to calculate it, obscures the amplitude of the social groups whose experience is reduced to fulfilling basic needs, while micro-resources actually create significant differences among this 59 percent of the Indian population. These micro-resources refer to caste status, home production, job status, and access to infrastructure depending on the area of residence. 


\section{The intermediate classes: 16 percent of the Indian population} tivated profile: urban, most often qualified, forward caste-and not necessarily the richest nor the largest number of owners, but very often professionals or business people. With their highly distinctive expenditure on reading, education and entertainment, this profile adds motor fuel, leather shoes, and industrial milk products. Finally, this cluster resembles the previous one by its lifestyle concerned with distinction, its qualification level and the frequency of upper castes; it differs by a noticeable divergence in levels of expenditure, which makes it a profile of the cultural bourgeoisie in the historical sense of the term (urban and entrepreneur, shopkeeper or liberal profession, rather than landowner).

Table 2 - The nine clusters by level of qualification

\begin{tabular}{|l|c|c|c|c|c|c|c|c|c|c|}
\hline & 1 & 2 & 3 & 4 & 5 & 6 & 7 & 8 & 9 & Pan-India \\
\hline Graduate and postgraduate & 2.1 & 1.3 & 4.1 & 9.4 & 14.3 & 18.9 & 17.5 & 13.6 & 16.2 & 7.8 \\
\hline Secondary and certificate & 11.6 & 11.1 & 15.4 & 22.6 & 23.3 & 24.7 & 32.6 & 25.0 & 28.4 & 19.1 \\
\hline Middle school & 14.4 & 14.8 & 14.6 & 17.1 & 15.1 & 12.7 & 14.6 & 17.5 & 18.8 & 15.0 \\
\hline Primary school & 13.0 & 13.1 & 13.3 & 12.4 & 11.4 & 10.9 & 10.8 & 13.1 & 15.7 & 12.6 \\
\hline
\end{tabular}




\begin{tabular}{|l|c|c|c|c|c|c|c|c|c|c|}
\hline Literate below primary & 13.6 & 15.4 & 13.5 & 11.4 & 10.4 & 12.4 & 8.4 & 7.6 & 11.6 & 12.3 \\
\hline Illiterate & 45.3 & 44.4 & 39.0 & 27.1 & 25.5 & 20.4 & 16.1 & 23.2 & 9.3 & 33.2 \\
\hline Total & 100 & 100 & 100 & 100 & 100 & 100 & 100 & 100 & 100 & 100 \\
\hline
\end{tabular}

NOTE: IN CLUSTER 6, 19 PERCENT BELONg TO A HOUSEHOLD IN WHICH THE REFERENCE PERSON HAS THE HIgHEST LEVEL OF EDUCATION, AS COMPARED WITH 17.5 PERCENT IN CLUSTER 7.

DATA: CONSUMER EXPENDITURE SURVEY, NATIONAL SAMPLE SURVEY 68TH ROUND (2011-2012)

52 In passing, we also find traces of an analytical element that we should be able to include in the survey using more refined caste indicators: not only is there a correlation between caste and class, but more specifically, on the one hand, in general there is a connection between caste and cultural capital and, on the other hand, a differentiation between upper economic castes (businessmen in the city, landowners in rural areas) and cultural upper castes (more often upper professionals or liberal professions).

The urban affluent class and the agrarian affluent class. Cluster 7 comprises 8 percent of the population and embodies the urban economic affluent class: comfort consumption associated with urban life (access to healthcare and travel, home rental, served meals and packaged beverages) in contrast to poor (dung cake) or rich rural consumption (related to the domestic space: interior furnishing, kitchen utensils as well as jewelry). In terms of properties, this profile combines professionals, qualification, distance from caste and religious minorities.

Cluster 8 (4 percent of the population) is the agrarian variant of the former, in the sense that it is spread over less dense urban areas and rural areas of average density (neither rural deserts, nor areas of subaltern urbanization). This echoes a result produced by the SFA on the richest 20 percent of the sample: axis 2 contrasted the highest urban densities with the highest rural densities and not the lowest, as was the case on the other global and partial SFAs (see Appendix 2). Richer than the former, particularly because they are more often landowners, the members of this clusters are more likely to be from an upper Hindu caste as well as to be professionals. In terms of consumption, these are people who invest highly in the domestic space (furnishings, home entertainment equipment) as well as in jewelry, healthcare and entertainment activities. This is obviously in complete opposition to budgets centered on poor rural consumption patterns.

The upper class. Cluster 9 is more difficult to interpret as it only represents 0.69 percent of the population and one of its principles of statistical aggregation is the high level of nonresponse to questions about the status of the residence, salaried status and profession. However, several indicators orient the interpretation towards the specific profile of an upper class: an average level of expenditure far above the others and high-level qualifications as well as residence in the densest urban areas (megapolises); elite consumption patterns typical of senior managers, owners, senior civil servants, rentiers or students-served meals, leather shoes, travel, home rental expenditure, packaged beverages. In addition, we know that the non-response rates regarding profession or source of income are very high among the richest, which would explain the principle behind the statistical aggregation of this cluster, based on non-responses. 
It is important to note that, unlike traditional stratification studies that often focus solely on the level of economic wealth, our multidimensional approach makes it possible to observe a decisive distinction between cultural and economic fractions within both the intermediate and upper classes. Table 2, which organizes the clusters by level of qualification, shows that clusters 6 and 7 are the highest on the educational scale, while their endowment in economic capital is relatively modest when compared to clusters 8 and 9.13

\section{Conclusion}

57 In that it attempts to develop a multidimensional approach, combining the level of wealth with other social properties, our analysis of the Indian social space allowed us to reveal the existence of a common scale of distribution of resources and statuses. This continuum of social positions is structured by the relationship to material constraints and supports the existence of a relatively unified Indian social space. Indeed, although it reveals a few slight variations, a more precise analysis of the different subspaces provides confirmation of the stability of this structure. Whether amongst the richest 20 percent, the poorest 30 percent or the intermediate 50 percent, people differentiate themselves from each other primarily by being more or less subject to material constraints (see Appendix 2).

Our analysis also revealed the existence of nine different ideal types that each group people with similar sociological profiles. This typology of polarities around which the Indian social space is structured allows us to sketch a nuanced portrait of Indian society that reveals the extreme diversity of lifestyles. In particular, the analysis brings to light the massive nature of the three categories that constitute the popular classes. On their own, they allow us to characterize the sociological profile of almost 60 percent of the Indian population. These three categories reveal subtle variations amongst the poorest: micro-resources that allow some to enjoy small comforts, like the purchase of tobacco or the use of spices for cooking, while others stand out by the extreme deprivation they are forced to endure. ${ }^{14}$ This study of the popular classes also enables us to relativize the importance to be attributed to the notion of "poverty threshold". The "poor popular classes" are, in fact, crossed, almost at the center, by this arbitrary line, but it does not, however, allow us to mark a clear break between lifestyles. The most sociologically relevant boundaries seem to be located lower down (between "extreme deprivation" and the "poor popular classes") or higher up (between the "poor popular classes" and the "stable popular classes").

The two types that constitute the intermediate classes (that represent 16 percent of the population) for their part, allow us to note a qualitative jump in terms of lifestyle. This jump is particularly embodied by the abandonment of subsidized food products and a wider variety of types of consumption. More qualified, more urban, more often of an upper caste, their lifestyles can be clearly distinguished from those of the popular classes by comfort consumption that seeks to affirm a comfortable status, marked for example by wearing leather shoes, the use of motorized vehicles or the occasional consumption of prepared meals (dhaba, street food, small restaurants, etc.).

The four types that constitute the affluent classes ( 25 percent of the population) reveal the existence of more contrasted lifestyles as one escapes the tyranny of need. The fractions within the upper classes, indeed, differ not only on the rural-urban scale, but 
also on the basis of their economic capital, their cultural capital and their caste. It is within these four most comfortable clusters that we find what economists or journalists often call the "middle classes". This observation hence leads to a certain wariness in the usage of this term, too often based on an economic definition that takes the level of consumption into account but pays little attention to variations in styles of consumption and at the outset, lifestyle. Moreover, if the so-called "middle" classes are reduced to those in fact located at the top of the society, there is a very high risk of confusion and of mixing up categories. We thus prefer to speak of "intermediate" classes rather than "middle classes".

61 The idea of middle class, as it is commonly apprehended, does away with the relational dimension necessarily contained in the term "middle" ("middle" classes only exist if so called "upper" and "lower" classes exist) and it doubly distorts the vision of Indian society. It leads not only to dissimulating the privileges enjoyed by the upper classes (which are no longer dominant but only "middle"), it also encourages to amalgamate all the groups that are not "middle" and are henceforth assimilated to the mass of those excluded from globalized consumption. Now, our analysis clearly shows the diversity of the popular and intermediate classes, which cannot be reduced to vast homogeneous categories.

To sum up, our work hence encourages us to be wary of prenotions like those of "middle class", "two-tier India", "urban-rural cleavage", or ideas drawn from politicobureaucratic language like "poverty threshold". While they produce the illusion of an immediate understanding of the complexity of Indian society, these ideas turn out to be dangerous simplifications and hamper a vision that is attentive to the various dimensions at work in the production of classifications in India. We hence think that the multidimensional approach to the Indian social space, initiated here, deserves to be explored in further detail. In particular, it makes it possible to empirically investigate the regional variations of the social structure that we have revealed: the methodology adopted allows us to vary the focal point of the analysis, from the social space at the national scale to its variants at the scale of each State. The comparative approach between regions, which is the most common in the Indian social sciences, but nonetheless has its weaknesses, which Aseema Sinha (2015) has underscored, could thus be revisited and consolidated by adding a unified and multidimensional representation of the Indian social space, something our analysis provides for the first time, along with synoptic summaries in the form of tables and diagrams.

\section{Appendix 1: Data and methods}

This appendix details the methodological framework of this study, by presenting thoroughly the data and the statistical method implemented here.

To start with, the consumption variables were selected from the overall basket and transformed into budgetary coefficients (consumption level per head divided by the total household consumption per head). We selected 37 detailed and aggregated (items that group families of goods ${ }^{15}$ ) budgetary items. This selection is based on budgetary items that allow us to highlight disparities in consumption, while maintaining the sociological coherence of the selected basket, which ends up representing close to 86 percent of the average total budget of Indian households (see column "Share in budget" in Table A1). Hence the selected basket does not include certain extremely rare consumer goods, or 
budgetary coefficients for durable goods, which are included in the analysis on the basis of possession (household appliances and means of transport, see column "Distribution" in Table A2).

Table A1 - Active variables used in the factorial analysis

\begin{tabular}{|c|c|c|c|c|c|c|c|c|c|}
\hline \multirow{2}{*}{ Budget item } & \multirow{2}{*}{$\begin{array}{l}\text { Share } \\
\text { in } \\
\text { budget } \\
(\%)\end{array}$} & \multicolumn{4}{|l|}{ Axis 1} & \multicolumn{4}{|l|}{ Axis 2} \\
\hline & & Contribution & Coord. & $\begin{array}{l}\text { Cos2 } \\
\text { SFA }\end{array}$ & $\begin{array}{l}\text { Coord. } \\
\text { SFA }\end{array}$ & Contribution & Coord. & $\begin{array}{l}\text { Cos2 } \\
\text { SFA }\end{array}$ & $\begin{array}{l}\text { Coord. } \\
\text { SFA }\end{array}$ \\
\hline Cereals & 11.85 & 6.46 & -0.47 & 0.00 & 0.03 & 4.86 & -0.34 & 0.24 & -0.49 \\
\hline $\begin{array}{l}\text { Fuel and light } \\
\text { (no dung } \\
\text { cake) }\end{array}$ & 8.97 & 6.35 & -0.47 & 0.22 & -0.47 & 0.92 & 0.15 & 0.04 & -0.21 \\
\hline $\begin{array}{l}\text { Milk and milk } \\
\text { products }\end{array}$ & 8.38 & 1.39 & 0.22 & 0.03 & 0.19 & 7.75 & -0.42 & 0.01 & -0.12 \\
\hline $\begin{array}{l}\text { Clothing and } \\
\text { bedding }\end{array}$ & 7.03 & 1.83 & -0.25 & 0.00 & -0.06 & 0.68 & -0.13 & 0.05 & -0.21 \\
\hline $\begin{array}{l}\text { Consumer } \\
\text { services (no } \\
\text { conveyance) }\end{array}$ & 4.55 & 2.74 & 0.31 & 0.03 & 0.17 & 0.14 & 0.06 & 0.06 & 0.25 \\
\hline $\begin{array}{l}\text { Vegetables } \\
\text { (no potato) }\end{array}$ & 3.92 & 10.03 & -0.59 & 0.23 & -0.48 & 1.25 & 0.17 & 0.08 & -0.28 \\
\hline $\begin{array}{l}\text { Egg. fish and } \\
\text { meat }\end{array}$ & 3.47 & 0.49 & -0.13 & 0.03 & -0.19 & 8.01 & 0.43 & 0.01 & 0.07 \\
\hline Pulses & 3.40 & 7.97 & -0.52 & 0.12 & -0.35 & 0.05 & -0.04 & 0.15 & -0.39 \\
\hline Conveyance & 2.99 & 0.40 & 0.12 & 0.01 & -0.09 & 2.41 & 0.24 & 0.03 & 0.16 \\
\hline Education & 2.82 & 6.91 & 0.49 & 0.15 & 0.39 & 0.38 & -0.09 & 0.04 & 0.21 \\
\hline Toilet articles & 2.53 & 1.47 & -0.22 & 0.09 & -0.30 & 2.39 & 0.24 & 0.00 & -0.05 \\
\hline Spices & 2.31 & 10.24 & -0.59 & 0.34 & -0.59 & 3.06 & 0.27 & 0.10 & -0.31 \\
\hline Motor fuel & 1.94 & 0.62 & 0.15 & 0.00 & -0.02 & 0.94 & 0.15 & 0.03 & 0.17 \\
\hline Beverages & 1.67 & 0.05 & 0.04 & 0.05 & -0.22 & 4.05 & 0.31 & 0.04 & 0.19 \\
\hline Rent & 1.56 & 3.51 & 0.35 & 0.02 & 0.14 & 1.02 & 0.15 & 0.08 & 0.28 \\
\hline $\begin{array}{l}\text { Medical } \\
\text { (institutional) }\end{array}$ & 1.55 & 1.01 & 0.19 & 0.02 & 0.16 & 0.11 & -0.05 & 0.00 & 0.06 \\
\hline
\end{tabular}




\begin{tabular}{|c|c|c|c|c|c|c|c|c|c|}
\hline Sugar & 1.53 & 1.22 & -0.20 & 0.00 & 0.05 & 14.16 & -0.57 & 0.22 & -0.47 \\
\hline served food & 1.52 & 2.00 & 0.26 & 0.01 & 0.08 & 1.62 & 0.19 & 0.13 & 0.36 \\
\hline Fruits & 1.41 & 1.43 & 0.22 & 0.00 & -0.05 & 4.55 & 0.33 & 0.06 & 0.24 \\
\hline $\begin{array}{l}\text { Packaged } \\
\text { processed } \\
\text { food }\end{array}$ & 1.40 & 0.10 & 0.06 & 0.00 & -0.03 & 0.68 & 0.13 & 0.03 & 0.18 \\
\hline $\begin{array}{l}\text { Cooked meals } \\
\text { for assistance }\end{array}$ & 1.40 & 1.42 & -0.22 & 0.00 & -0.06 & 0.01 & -0.02 & 0.02 & -0.13 \\
\hline Potato & 1.20 & 7.55 & -0.51 & 0.05 & -0.23 & 3.78 & -0.30 & 0.09 & -0.29 \\
\hline $\begin{array}{l}\text { Entertainment } \\
\text { (cinema, club, } \\
\text { etc.) }\end{array}$ & 1.17 & 2.36 & 0.28 & 0.00 & 0.04 & 4.12 & 0.31 & 0.10 & 0.32 \\
\hline Tobacco & 1.14 & 0.90 & -0.18 & 0.02 & -0.15 & 0.01 & 0.01 & 0.01 & -0.09 \\
\hline Cereals PDS & 0.99 & 4.38 & -0.39 & 0.26 & -0.51 & 7.43 & 0.42 & 0.00 & 0.02 \\
\hline Dung cake & 0.90 & 1.89 & -0.25 & 0.00 & 0.03 & 10.67 & -0.50 & 0.11 & -0.33 \\
\hline Reading & 0.77 & 3.65 & 0.35 & 0.12 & 0.35 & 0.85 & -0.14 & 0.02 & 0.15 \\
\hline Intoxicants & 0.73 & 0.07 & -0.05 & 0.02 & -0.13 & 1.61 & 0.19 & 0.01 & 0.08 \\
\hline $\begin{array}{l}\text { Footwear (no } \\
\text { leather) }\end{array}$ & 0.69 & 2.98 & -0.32 & 0.04 & -0.20 & 0.46 & -0.10 & 0.09 & -0.29 \\
\hline Jewels & 0.57 & 0.92 & 0.18 & 0.03 & 0.16 & 0.00 & 0.00 & 0.01 & 0.09 \\
\hline Leather shoes & 0.50 & 2.61 & 0.30 & 0.05 & 0.22 & 0.37 & -0.09 & 0.02 & 0.13 \\
\hline Pan & 0.34 & 0.37 & -0.11 & 0.02 & -0.12 & 1.39 & 0.18 & 0.00 & 0.06 \\
\hline $\begin{array}{l}\text { Crockery and } \\
\text { utensils }\end{array}$ & 0.23 & 0.19 & -0.08 & 0.00 & 0.01 & 0.17 & -0.06 & 0.00 & -0.05 \\
\hline Sugar PDS & 0.15 & 2.93 & -0.32 & 0.24 & -0.49 & 9.96 & 0.48 & 0.01 & 0.09 \\
\hline $\begin{array}{l}\text { Goods for } \\
\text { recreation } \\
\text { (TV, DVD, } \\
\text { etc.) }\end{array}$ & 0.12 & 0.34 & 0.11 & 0.00 & 0.04 & 0.09 & 0.05 & 0.01 & 0.09 \\
\hline Furniture & 0.09 & 0.31 & 0.10 & 0.01 & 0.07 & 0.04 & 0.03 & 0.01 & 0.09 \\
\hline Khesari & 0.04 & 0.89 & -0.17 & 0.01 & -0.07 & 0.00 & -0.01 & 0.01 & -0.08 \\
\hline
\end{tabular}


NOTE: BUDgETARY ITEMS ARE USED IN THE FACTOR ANALYSIS AS ACTIVE VARIABLES. THE

CONSUMPTION OF CEREALS REPRESENTS ON AVERAgE 12 PERCENT OF THE TOTAL CONSUMPTION. THE CONTRIBUTIONS OF THE BUDgETARY ITEMS FOR THE FIRST TWO FACTORS OF THE PCA ARE PRESENTED, ALONg WITH THE COORDINATES OF THE SFA ("gLOBAL" ANALYSES).

Table A2 - Supplementary variables (1): Ownership of durable goods and use of AYUSH treatments

\begin{tabular}{|c|c|c|c|c|c|c|c|}
\hline & & & & Axis 1 & & Axis 2 & \\
\hline & & Modality & (\%) & $\begin{array}{l}\text { Coord. } \\
\text { PCA }\end{array}$ & $\begin{array}{l}\text { Coord. } \\
\text { SFA }\end{array}$ & $\begin{array}{l}\text { Coord. } \\
\text { PCA }\end{array}$ & $\begin{array}{l}\text { Coord. } \\
\text { SFA }\end{array}$ \\
\hline & Ayush & Yes & 30.14 & 0.12 & 0.08 & -0.07 & 0.03 \\
\hline & & No & 69.85 & -0.05 & -0.03 & 0.03 & -0.01 \\
\hline & & Unknown & 0.00 & -0.77 & -0.10 & 1.25 & -0.36 \\
\hline & Bicycle & Yes & 58.36 & -0.18 & 0.04 & -0.22 & -0.02 \\
\hline & & No & 41.64 & 0.26 & -0.04 & 0.30 & 0.02 \\
\hline & Scooter & Yes & 27.27 & 1.32 & 0.53 & -0.10 & 0.26 \\
\hline & & No & 72.73 & -0.49 & -0.24 & 0.04 & -0.12 \\
\hline & Car & Yes & 4.47 & 2.32 & 0.70 & -0.07 & 0.41 \\
\hline & & No & 95.53 & -0.11 & -0.05 & 0.00 & -0.03 \\
\hline & Clock & Yes & 87.00 & 0.20 & 0.07 & 0.04 & 0.05 \\
\hline Possessed & & No & 13.00 & -1.33 & -0.57 & -0.24 & -0.36 \\
\hline items & Computer & Yes & 5.28 & 2.75 & 0.87 & 0.15 & 0.67 \\
\hline & & No & 94.72 & -0.15 & -0.06 & -0.01 & -0.05 \\
\hline & $\begin{array}{l}\text { Mobile } \\
\text { handset }\end{array}$ & Yes & 85.22 & 0.28 & 0.12 & -0.03 & 0.08 \\
\hline & & No & 14.78 & -1.62 & -0.74 & 0.17 & -0.45 \\
\hline & $\begin{array}{l}\text { Landline } \\
\text { phone }\end{array}$ & Yes & 5.53 & 2.05 & 0.60 & 0.33 & 0.35 \\
\hline & & No & 94.47 & -0.12 & -0.05 & -0.02 & -0.03 \\
\hline & Electric fan & Yes & 71.89 & 0.45 & 0.14 & 0.12 & 0.11 \\
\hline & & No & 28.11 & -1.16 & -0.39 & -0.30 & -0.30 \\
\hline & Refrigerator & Yes & 20.93 & 1.80 & 0.53 & 0.04 & 0.37 \\
\hline
\end{tabular}




\begin{tabular}{|l|l|l|l|l|l|l|l|}
\hline & No & 79.07 & -0.48 & -0.19 & -0.01 & -0.14 \\
\hline
\end{tabular}

NOTE: THE OWNERSHIP OF DURABLE gOODS AND THE USE OF AYUSH TREATMENTS IS INCLUDED IN THE ANALYSIS AS SUPPLEMENTARY VARIABLES. 30.14 PERCENT OF INDIANS LIVE IN HOUSEHOLDS THAT USE AYUSH TREATMENTS. THE COORDINATES OF THE MODALITIES (YES/NO) OF THE PCA AND OF THE SFA ARE PRESENTED IN THE COLUMNS.

Secondly, we selected 14 social position variables that allow us to grasp different segmentations of Indian society, mainly the level of consumption, the living environment (urban or rural, and geographic ${ }^{16}$ ), caste, religion and social class. The latter was constructed using the class schema developed by Vaid (2012), to date the only schema that offers a synthetic representation of social classes in Indian society.

Table A3 - Supplementary variables (2): Social positions of households

\begin{tabular}{|c|c|c|c|c|c|c|c|}
\hline & & \multirow[b]{2}{*}{ Modality } & \multirow{2}{*}{$\begin{array}{l}\text { Distribution } \\
\text { (\%) }\end{array}$} & \multicolumn{2}{|l|}{ Axis 1} & \multicolumn{2}{|l|}{ Axis 2} \\
\hline & & & & $\begin{array}{l}\text { Coord. } \\
\text { PCA }\end{array}$ & $\begin{array}{l}\text { Coord. } \\
\text { SFA }\end{array}$ & $\begin{array}{l}\text { Coord. } \\
\text { PCA }\end{array}$ & $\begin{array}{l}\text { Coord. } \\
\text { SFA }\end{array}$ \\
\hline \multirow{14}{*}{$\begin{array}{l}\text { Standard of } \\
\text { living }\end{array}$} & \multirow{12}{*}{ MPCE } & P0-P5 & 5.00 & -2.49 & -1.15 & -0.06 & -0.63 \\
\hline & & P5-P10 & 5.00 & -1.88 & -0.63 & -0.40 & -0.65 \\
\hline & & P10-P20 & 10.00 & -1.49 & -0.56 & -0.32 & -0.55 \\
\hline & & P20-P30 & 10.00 & -1.08 & -0.40 & -0.26 & -0.48 \\
\hline & & P30-P40 & 10.00 & -0.74 & -0.32 & -0.21 & -0.38 \\
\hline & & P40-P50 & 10.00 & -0.37 & -0.24 & -0.03 & -0.30 \\
\hline & & P50-P60 & 10.00 & 0.00 & -0.13 & 0.06 & -0.18 \\
\hline & & P60-P70 & 10.00 & 0.41 & -0.01 & 0.16 & -0.05 \\
\hline & & P70-P80 & 10.00 & 0.94 & 0.15 & 0.18 & 0.13 \\
\hline & & P80-P90 & 10.00 & 1.63 & 0.36 & 0.28 & 0.36 \\
\hline & & P90-P95 & 5.00 & 2.36 & 0.55 & 0.35 & 0.66 \\
\hline & & P95-P100 & 5.00 & 3.41 & 0.94 & 0.38 & 0.97 \\
\hline & \multirow[b]{2}{*}{ Ration card } & $\begin{array}{l}\text { Ration card } \\
\text { holder }\end{array}$ & 84.11 & -0.10 & -0.07 & 0.04 & -0.04 \\
\hline & & $\begin{array}{l}\text { No ration card } \\
\text { hold }\end{array}$ & 15.88 & 0.50 & 0.29 & -0.18 & 0.17 \\
\hline
\end{tabular}




\begin{tabular}{|c|c|c|c|c|c|c|c|}
\hline & & $\begin{array}{ll}\text { Ration } & \text { card } \\
\text { unknown } & \end{array}$ & 0.02 & 0.66 & 0.80 & -1.43 & -0.08 \\
\hline & \multirow{6}{*}{ Land owned } & No land owned & 10.51 & 1.31 & 0.21 & 0.77 & 0.55 \\
\hline & & $\mid \begin{array}{l}0-1 \text { acre land } \\
\text { owned }\end{array}$ & 58.05 & -0.19 & -0.16 & 0.08 & -0.04 \\
\hline & & $\begin{array}{l}\text { 1-5 acres land } \\
\text { owned }\end{array}$ & 23.45 & -0.28 & 0.10 & -0.30 & -0.15 \\
\hline & & $\begin{array}{l}\text { 5-10 acres land } \\
\text { owned }\end{array}$ & 5.29 & 0.30 & 0.37 & $\mid-0.66$ & -0.09 \\
\hline & & $\begin{array}{l}10-20 \text { acres land } \\
\text { owned }\end{array}$ & 2.02 & 0.71 & 0.52 & $\mid-0.73$ & -0.12 \\
\hline & & $\begin{array}{l}20+\text { acres land } \\
\text { owned }\end{array}$ & 0.67 & 1.17 & 0.68 & -0.73 & -0.01 \\
\hline \multirow[t]{11}{*}{$\begin{array}{l}\text { Social } \\
\text { category }\end{array}$} & \multirow{11}{*}{ Social class } & $\begin{array}{l}\text { Farmers-owners } \\
\text { (large and } \\
\text { medium) }\end{array}$ & 6.53 & 0.35 & 0.47 & -0.78 & -0.18 \\
\hline & & $\begin{array}{l}\text { Farmers small } \\
\text { and tenants }\end{array}$ & 15.10 & -0.42 & 0.10 & -0.50 & -0.31 \\
\hline & & $\begin{array}{l}\text { Lower } \\
\text { agriculturists }\end{array}$ & 21.95 & -1.08 & $\mid-0.43$ & 0.09 & -0.38 \\
\hline & & $\begin{array}{l}\text { Higher } \\
\text { professionals }\end{array}$ & 3.69 & 2.20 & 0.58 & 0.27 & 0.54 \\
\hline & & $\begin{array}{l}\text { Lower } \\
\text { Professionals }\end{array}$ & 4.27 & 1.47 & 0.49 & 0.11 & 0.37 \\
\hline & & Business & 6.77 & 0.96 & 0.18 & 0.16 & 0.18 \\
\hline & & Petty business & 0.86 & -0.33 & $\mid-0.37$ & 0.13 & -0.04 \\
\hline & & $\begin{array}{l}\text { Routine non } \\
\text { Manual }\end{array}$ & 7.25 & 0.80 & 0.14 & 0.21 & 0.19 \\
\hline & & $\begin{array}{l}\text { Lower Routine- } \\
\text { non Manuel }\end{array}$ & 2.53 & 0.67 & -0.03 & 0.31 & 0.20 \\
\hline & & Skilled workers & 7.95 & 0.63 & -0.05 & 0.37 & 0.08 \\
\hline & & $\begin{array}{l}\text { Semi and } \\
\text { unskilled } \\
\text { workers }\end{array}$ & 19.07 & -0.44 & -0.44 & 0.09 & -0.19 \\
\hline
\end{tabular}




\begin{tabular}{|c|c|c|c|c|c|c|}
\hline & $\begin{array}{l}\text { Occupation } \\
\text { unknown }\end{array}$ & 4.03 & 0.73 & 0.11 & 0.26 & 0.28 \\
\hline \multirow{3}{*}{ Salary } & $\begin{array}{l}\text { Regular salary } \\
\text { earner }\end{array}$ & 20.95 & 1.23 & 0.27 & 0.32 & 0.34 \\
\hline & $\begin{array}{l}\text { No regular salary } \\
\text { earner }\end{array}$ & 79.04 & -0.33 & -0.11 & -0.09 & -0.13 \\
\hline & Salary unknown & 0.01 & 0.75 & 0.48 & 0.41 & 0.58 \\
\hline \multirow{7}{*}{ Education } & illiterate & 33.24 & -0.81 & -0.42 & -0.15 & -0.34 \\
\hline & $\begin{array}{l}\text { literate below } \\
\text { primary }\end{array}$ & 12.28 & -0.48 & -0.24 & 0.13 & -0.23 \\
\hline & Primary school & 12.60 & -0.18 & -0.17 & 0.14 & -0.09 \\
\hline & Middle school & 15.03 & 0.10 & 0.00 & 0.09 & -0.04 \\
\hline & $\begin{array}{l}\text { Secondary and } \\
\text { certificate }\end{array}$ & 19.08 & 0.90 & 0.32 & -0.02 & 0.24 \\
\hline & $\begin{array}{l}\text { Graduate and } \\
\text { postgraduate }\end{array}$ & 7.76 & 2.12 & 0.65 & 0.08 & 0.60 \\
\hline & Edu unknown & 0.01 & -0.48 & 0.00 & -0.64 & 0.57 \\
\hline \multirow{5}{*}{$\begin{array}{l}\text { Reserved } \\
\text { group } \\
\text { (caste) }\end{array}$} & STs & 8.93 & -1.13 & -0.19 & 0.47 & -0.11 \\
\hline & $\mathrm{SCs}$ & 19.03 & -0.55 & -0.33 & 0.01 & -0.17 \\
\hline & OBCs & 44.06 & 0.00 & 0.01 & -0.07 & -0.07 \\
\hline & Upper castes & 27.97 & 0.74 & 0.25 & -0.05 & 0.23 \\
\hline & Caste unknown & 0.01 & -1.37 & 0.26 & -0.01 & 0.59 \\
\hline \multirow{8}{*}{ Religion } & Hinduism & 81.49 & -0.01 & 0.01 & -0.02 & -0.01 \\
\hline & Islam & 13.64 & -0.20 & -0.18 & 0.06 & 0.03 \\
\hline & Christianity & 2.23 & 0.75 & 0.13 & 1.21 & 0.04 \\
\hline & Sikhism & 1.61 & 1.07 & 0.12 & -1.31 & 0.00 \\
\hline & Jainism & 0.25 & 2.39 & 0.69 & -0.03 & 0.76 \\
\hline & Buddhism & 0.59 & -0.15 & -0.06 & 0.57 & -0.10 \\
\hline & Zoroastrianism & 0.00 & 4.52 & 1.05 & 1.46 & -1.10 \\
\hline & Religion Others & 0.19 & -0.38 & 0.19 & 0.53 & -0.15 \\
\hline
\end{tabular}




\begin{tabular}{|c|c|c|c|c|c|c|c|}
\hline & & $\begin{array}{l}\text { Religion } \\
\text { unknown }\end{array}$ & 0.00 & 1.63 & 1.23 & 1.02 & -0.11 \\
\hline & \multirow{5}{*}{$\begin{array}{l}\text { Overlap } \\
\text { Hindu/ } \\
\text { reserved } \\
\text { group }\end{array}$} & Hindu low caste & 61.56 & -0.33 & -0.12 & 0.01 & -0.12 \\
\hline & & $\begin{array}{l}\text { Hindu Upper } \\
\text { castes }\end{array}$ & 19.92 & 0.96 & 0.33 & -0.14 & 0.27 \\
\hline & & $\begin{array}{l}\text { Non Hindu low } \\
\text { caste }\end{array}$ & 10.46 & -0.04 & -0.05 & 0.06 & -0.04 \\
\hline & & $\begin{array}{l}\text { Non-Hindu } \\
\text { middle \& higher } \\
\text { castes }\end{array}$ & 8.04 & 0.19 & 0.00 & 0.16 & 0.13 \\
\hline & & $\begin{array}{ll}\text { Cross } & \text { Caste } \\
\text { unknown } & \end{array}$ & 0.01 & -1.35 & 0.27 & 0.01 & 0.61 \\
\hline \multirow[t]{16}{*}{$\begin{array}{l}\text { Geographic } \\
\text { environment }\end{array}$} & \multirow[t]{16}{*}{ State } & $\begin{array}{l}\text { Jammu } \quad \& \\
\text { Kashmir }\end{array}$ & 0.89 & 0.28 & & 1.11 & \\
\hline & & $\begin{array}{l}\text { Himachal } \\
\text { Pradesh }\end{array}$ & 0.59 & 0.26 & & 0.49 & \\
\hline & & Punjab & 2.31 & 1.00 & & -1.17 & \\
\hline & & Chandigarh & 0.09 & 1.73 & & 0.03 & \\
\hline & & Uttaranchal & 0.86 & 0.18 & & 0.00 & \\
\hline & & Haryana & 2.25 & 1.15 & & -1.34 & \\
\hline & & Delhi & 1.14 & 1.63 & & 0.19 & \\
\hline & & Rajasthan & 5.54 & 0.64 & & -0.86 & \\
\hline & & Uttar Pradesh & 16.54 & -0.39 & & -1.17 & \\
\hline & & Bihar & 8.47 & -0.73 & & -0.93 & \\
\hline & & Sikkim & 0.04 & 0.82 & & 1.23 & \\
\hline & & $\begin{array}{l}\text { Arunachal } \\
\text { Pradesh }\end{array}$ & 0.09 & -0.28 & & 1.59 & \\
\hline & & Nagaland & 0.11 & 0.91 & & 0.39 & \\
\hline & & Manipur & 0.21 & 0.54 & & 0.11 & \\
\hline & & Mizoram & 0.09 & -0.40 & & 1.99 & \\
\hline & & Tripura & 0.32 & -0.83 & & 2.27 & \\
\hline
\end{tabular}




\begin{tabular}{|c|c|c|c|c|c|c|}
\hline & Meghalaya & 0.24 & 0.66 & & 1.81 & \\
\hline & Assam & 2.54 & -1.00 & & 1.60 & \\
\hline & West Bengal & 7.68 & -0.47 & & 0.17 & \\
\hline & Jharkhand & 2.49 & -0.74 & & -0.66 & \\
\hline & Orissa & 3.35 & -1.42 & & 0.36 & \\
\hline & Chhattisgarh & 2.18 & -1.75 & & 0.25 & \\
\hline & Madhya Pradesh & 5.92 & -0.68 & & -0.40 & \\
\hline & Gujarat & 5.02 & 0.49 & & -0.06 & \\
\hline & Daman \& Diu & 0.01 & 0.82 & & 0.92 & \\
\hline & D \& N Haveli & 0.03 & -0.15 & & 0.75 & \\
\hline & Maharashtra & 9.50 & 0.52 & & 0.33 & \\
\hline & Andhra Pradesh & 7.22 & 0.59 & & 0.92 & \\
\hline & Karnataka & 5.11 & 0.62 & & 0.81 & \\
\hline & Goa & 0.11 & 2.05 & & 1.49 & \\
\hline & Lakshadweep & 0.00 & 0.49 & & 3.25 & \\
\hline & Kerala & 2.84 & 1.46 & & 1.54 & \\
\hline & Tamil Nadu & 6.10 & 0.46 & & 2.15 & \\
\hline & Pondicherry & 0.10 & 1.16 & & 1.44 & \\
\hline & A \& N Islands & 0.03 & -0.51 & & 3.00 & \\
\hline & Rural & 71.43 & -0.49 & -0.09 & -0.16 & -0.20 \\
\hline & Urban & 28.57 & 1.22 & 0.19 & 0.39 & 0.43 \\
\hline $\begin{array}{l}\text { Density } \\
\text { (inhab / }\end{array}$ & $\begin{array}{ll}\text { Density } & \text { rural } \\
\text { very low } & \end{array}$ & 1.29 & -0.54 & -0.10 & 0.47 & -0.22 \\
\hline & Density rural low & 12.59 & -0.70 & -0.14 & 0.07 & -0.27 \\
\hline & $\begin{array}{l}\text { Density rural } \\
\text { medium }\end{array}$ & 21.03 & -0.33 & -0.11 & 0.22 & -0.22 \\
\hline & $\begin{array}{l}\text { Density rural } \\
\text { medium high }\end{array}$ & 20.46 & -0.51 & -0.03 & -0.41 & -0.20 \\
\hline
\end{tabular}




\begin{tabular}{|c|c|c|c|c|c|c|c|}
\hline & & $\begin{array}{ll}\text { Density rural } \\
\text { high }\end{array}$ & 15.86 & -0.53 & -0.06 & -0.57 & -0.10 \\
\hline & & $\begin{array}{ll}\text { Density } & \text { rural } \\
\text { very high } & \end{array}$ & 0.19 & 1.56 & 0.18 & 0.39 & -0.21 \\
\hline & & $\begin{array}{ll}\text { Density } & \text { urban } \\
\text { very low } & \end{array}$ & 0.33 & 1.07 & 0.33 & 0.24 & 0.21 \\
\hline & & $\begin{array}{l}\text { Density urban } \\
\text { low }\end{array}$ & 3.02 & 0.79 & 0.21 & 0.27 & 0.38 \\
\hline & & $\begin{array}{ll}\text { Density urban } \\
\text { medium }\end{array}$ & 6.94 & 1.09 & 0.22 & 0.46 & 0.34 \\
\hline & & $\begin{array}{l}\text { Density urban } \\
\text { medium high }\end{array}$ & 7.41 & 1.20 & 0.11 & 0.31 & 0.42 \\
\hline & & $\begin{array}{l}\text { Density urban } \\
\text { high }\end{array}$ & 6.21 & 1.01 & 0.07 & 0.21 & 0.59 \\
\hline & & $\begin{array}{l}\text { Density urban } \\
\text { very high }\end{array}$ & 4.67 & 2.02 & 0.34 & 0.73 & 0.66 \\
\hline & & $\begin{array}{ll}\text { Density } & \text { urban } \\
\text { unknown } & \end{array}$ & 0.00 & 1.14 & 0.13 & 0.45 & -0.06 \\
\hline & & $\begin{array}{ll}\text { Density } & \text { rural } \\
\text { unknown } & \end{array}$ & 0.00 & 0.63 & 0.37 & 0.04 & -0.20 \\
\hline \multirow{9}{*}{$\begin{array}{l}\text { Structure of } \\
\text { the household }\end{array}$} & \multirow{2}{*}{ Joint family } & No joint fam & 55.91 & -0.06 & -0.06 & 0.15 & 0.06 \\
\hline & & Joint family & 44.09 & 0.07 & 0.11 & $\mid-0.19$ & -0.10 \\
\hline & \multirow{2}{*}{$\begin{array}{l}\text { Live-in } \\
\text { domestic } \\
\text { staff }\end{array}$} & No servant & 99.50 & -0.01 & 0.00 & 0.00 & 0.00 \\
\hline & & Servant & 0.50 & 1.65 & 0.57 & 0.02 & 0.33 \\
\hline & \multirow{5}{*}{$\begin{array}{l}\text { Status of } \\
\text { the } \\
\text { residence }\end{array}$} & No dwelling unit & 0.06 & -1.45 & -0.39 & 0.24 & -0.32 \\
\hline & & $\begin{array}{l}\text { Hiring dwelling } \\
\text { unit }\end{array}$ & 9.61 & 1.89 & 0.40 & 0.78 & 0.74 \\
\hline & & Dwelling owner & 88.58 & -0.20 & -0.05 & -0.10 & -0.10 \\
\hline & & $\begin{array}{l}\text { Other kind of } \\
\text { dwelling unit }\end{array}$ & 1.75 & -0.06 & -0.14 & 0.66 & 0.19 \\
\hline & & $\begin{array}{l}\text { Dwelling } \\
\text { unknown }\end{array}$ & 0.00 & 1.92 & 0.44 & 0.10 & $\mid-0.16$ \\
\hline
\end{tabular}


NOTE: SOCIAL POSITION INDICATORS ARE INCLUDED IN THE ANALYSIS AS SUPPLEMENTARY VARIABLES IN ORDER TO INTERPRET THE FACTORIAL PLANS. THE SHARE OF EACH MODALITY, ALONg WITH THE COORDINATES IN THE PCA AND THE SFA ARE PRESENTED HERE. THE COORDINATES OF THE DIFFERENT STATES IN THE SFA ARE NOT PRESENT SINCE THE STATE VARIABLE IS USED TO “NEUTRALIZE" THE FACTOR PLAN. on the basis of the main profession of the household. As only 22 percent of women between the ages of 15 and 59 belong to the active population, the social class is primarily a reflection of the male head of the household's economic activity. Vaid's schema was produced by modifying Goldthorpe's typology of "occupations" in British society, to adapt it to Indian society, more specifically by associating rural and urban professions in the same grid (Table A4). Farmers (over 40 percent of the active population) are thus divided into three categories, according to their status as day laborers, sharecroppers or landowners. The breakdown of class by sector of residence also shows that this grid of analysis is well suited to India. Although certain categories are over-represented in urban areas and others in rural areas, this schema clearly offers a synthetic view of social classes in India (Table A5). The construction of this variable, based on the National Classification of Occupations-2004 nomenclature (designed by the Directorate of General Training of the Ministry of Skill Development and Entrepreneurship, based on the ISCO-1988 nomenclature), nonetheless leaves the social class of 4 percent of the population, located more amongst the richest and most urban fractions of the social space, in abeyance. Whether it be due to the absence of a profession (rentiers) or the refusal to declare their economic activity, we can conjecture about this fraction of the social space that is impossible to grasp. The survey also records whether the profession is a salaried one or not, which allows us to make a distinction between the self-employed, day laborers and salaried employees. 
Table A4 - Class schema used by Divya Vaid (Excerpt from Vaid 2005)

\begin{tabular}{|c|c|}
\hline I & $\begin{array}{l}\text { Higher professionals, administrators } \\
\text { and Officials; Elected officials } \\
\text { (Central/State level); Managers }\end{array}$ \\
\hline II & $\begin{array}{l}\text { Low Professionals, administrators and } \\
\text { officials; Elected Officials (District } \\
\text { level); technicians, supervisors }\end{array}$ \\
\hline IIla & $\begin{array}{l}\text { Routine non-manual employees } \\
\text { (high), Other administrators, Class IV } \\
\text { (peons etc), sales executives, Sales } \\
\text { persons, shop assistants, Traditional } \\
\text { clerks, Class III (clerical) }\end{array}$ \\
\hline IIIlb & $\begin{array}{l}\text { Routine Non-Manual low grade - } \\
\text { Waiters, Washer men, barbers, ayahs, } \\
\text { other service etc. }\end{array}$ \\
\hline IVa & $\begin{array}{l}\text { Big business (with } 7 \text { +employees), } \\
\text { medium business ( } 3-7 \text { employees), } \\
\text { small business ( } 1-2 \text { employees or } \\
\text { family workers) }\end{array}$ \\
\hline $\mathrm{IVb}$ & Petty Shopkeepers, rentiers \\
\hline IVc & $\begin{array}{l}\text { Farmers (Owners) with more than } 5 \\
\text { acres of land }\end{array}$ \\
\hline IVd & $\begin{array}{l}\text { Small Farmers (Owners) with } 0-5 \\
\text { acres of land; Tenant farmers ( } 5+ \\
\text { acres) }\end{array}$ \\
\hline VI & Skilled manual workers \\
\hline VIla & $\begin{array}{l}\text { Semi- and unskilled manual workers } \\
\text { (not in agriculture etc.) }\end{array}$ \\
\hline VIIb & $\begin{array}{l}\text { Lower Agriculturalists - Agricultural } \\
\text { Labourers and Non-cultivators; Small } \\
\text { Tenants ( } 0-5 \text { acres) }\end{array}$ \\
\hline
\end{tabular}

Table A5 - Social composition of the rural and urban Indian population by class.

\begin{tabular}{|l|l|l|l|}
\hline & All India & Rural & Urban \\
\hline Higher professionals & 3.69 & 1.29 & 9.7 \\
\hline Lower professionals & 4.27 & 2.81 & 7.94 \\
\hline Routine non-manual & 7.25 & 4.63 & 13.81 \\
\hline Lower Routine non-manual & 2.53 & 1.69 & 4.65 \\
\hline Business & 6.77 & 4 & 13.67 \\
\hline Petty business & 0.86 & 0.67 & 1.32 \\
\hline Skilled workers & 7.95 & 5.06 & 15.18 \\
\hline Semi and unskilled workers & 19.07 & 17.91 & 21.94 \\
\hline Farmers-owners (large and medium) & 6.53 & 8.64 & 1.23 \\
\hline Farmers small and tenants & 15.1 & 20.53 & 1.52 \\
\hline Lower agriculturists & 21.95 & 29.46 & 3.17 \\
\hline
\end{tabular}




\begin{tabular}{|l|l|l|l|}
\hline Occupation unknown & 4.03 & 3.3 & 5.88 \\
\hline Total & 100 & 100 & 100 \\
\hline
\end{tabular}

NOTE: 3.7 PERCENT OF THE INDIAN POPULATION LIVES IN A HOUSEHOLD WHERE THE MAIN PROFESSIONAL ACTIVITY BELONgS TO THE HIgHER PROFESSIONALS SOCIAL CLASS.

The social structure of caste is reduced to a study of official categories: Scheduled caste (SC), Scheduled Tribes (ST), Other Backward Classes (OBC). We further clustered all the groups that do not benefit from reservations under the label "Forward castes" or "Upper castes". A knowledge of the religion of the households also allows us to specify the congruence between caste and class, as Divya Vaid showed. She thus distinguishes the Muslim minority (13.5 percent of the estimated population in our survey) from the rest of the population, and establishes that this category is very close to the SCs and STs. This justifies our creation of a variable combining Forward caste or low castes (combining ST, $\mathrm{SC}$ and $\mathrm{OBC}$ ) with the Hindu religion (81 percent of the estimated population) or religious minority (the non-Hindus are Muslim, 13.5 percent, Christian, 2.3 percent, Sikh, 1.6 percent, Jain 0.25 percent or belong to other religious minorities).

Table A6 - Distribution of the population between Hindu and nonHindu forward castes and Hindu and non-Hindu lower castes

\begin{tabular}{|l|l|l|l|}
\hline Modalities & Pan-India & Rural & Urban \\
\hline Hindu Forward castes & 20.0 & 15.9 & 29.8 \\
\hline Non Hindu forward castes & 8.0 & 7.1 & 10.5 \\
\hline Hindu low caste & 61.6 & 67.2 & 47.5 \\
\hline Non Hindu low caste & 10.4 & 9.8 & 12.2 \\
\hline TOTAL & 100 & 100 & 100 \\
\hline
\end{tabular}

NOTE: 20 PERCENT OF THE POPULATION BELONgS TO THE FORWARD HINDU CASTES.

Lastly the household's geographical location is taken into account through the State or Union Territory of residence and the urban or rural living environment. But in order to transcend the latter dichotomy, a variable showing population density by district was introduced in an attempt to envisage more precise levels of urban development and rural isolation. This variable was constructed from the 2011 Census data and follows a classification of 6 density levels per district, distinguishing the urban and the rural. This provides a variable with 12 modalities (Table A7). Indeed, it is quite surprising to note that apart from the high and very high density modalities, the rural environment is overrepresented (in comparison to the total proportion of inhabitants in rural environments) in all the density categories, including for the medium high and medium densities. This result is yet another argument reinforcing the inadequacy of the categories rural and urban, and the relevance of the introduction of our variable. The latter is nonetheless to 
be considered cautiously as in itself it does not represent an indicator of urban development.

Table A7 - Proportion of the population in each density category, by urban and rural Census categories

\begin{tabular}{|l|c|c|c|}
\hline & Rural & Urban & Total \\
\hline Density very high & 3.8 & 96.2 & 100 \\
\hline Density high & 71.3 & 28.7 & 100 \\
\hline Density medium high & 73.4 & 26.6 & 100 \\
\hline Density medium & 75.2 & 24.8 & 100 \\
\hline Density low & 80.7 & 19.3 & 100 \\
\hline Density very low & 79.9 & 20.1 & 100 \\
\hline Density unknown & 72.5 & 27.5 & 100 \\
\hline Total & 71.4 & 28.6 & 100 \\
\hline
\end{tabular}

NOTE: 3.8 PERCENT OF RURAL INHABITANTS LIVE IN A VERY HIgH DENSITY ZONE.

\section{Principal component analysis and standard factor analysis}

70 The next stage consisted of producing a Principal Component Analysis (PCA) that permits a graphic representation on two-dimensional planes, of the correlations measured between the budget variables (active variables ${ }^{17}$ ), while seeking associations with social position variables (supplementary variables). The analysis is weighted using the survey weight, which results from the weighting adjustment of random sampling design by the NSSO. The use of the weighting coefficient multiplied by the number of people in the household (a choice in line with other works that use this type of surveys for consumption budgets) can be equated to studying the consumption of the average person in each household. Here we only interpret the first plane made up of the two main dimensions of the PCA (see Figure A1 for the cloud of individuals)-those that best resume the inertia of the correlations between the active variables (or in other words, provide the most information, see Table A8 for the variance explained by the different factors).

Table A8 - Eigenvalues and inertia of all factors of PCA

\begin{tabular}{|l|l|l|l|l|l|}
\hline Factor & $\begin{array}{l}\text { Proper } \\
\text { value }\end{array}$ & $\begin{array}{l}\text { Variance } \\
(\%)\end{array}$ & $\begin{array}{l}\text { Cumulative } \\
\text { variance (\%) }\end{array}$ & $\begin{array}{l}\text { Modified rate } \\
(\%)\end{array}$ & $\begin{array}{l}\text { Cumulative modified } \\
\text { rate (\%) }\end{array}$ \\
\hline 1 & 3.42 & 9.25 & 9.25 & 24.10 & 24.10 \\
\hline
\end{tabular}




\begin{tabular}{|c|c|c|c|c|c|}
\hline 2 & 2.33 & 6.29 & 15.54 & 11.11 & 35.21 \\
\hline 3 & 1.83 & 4.94 & 20.48 & 6.83 & 42.04 \\
\hline 4 & 1.63 & 4.41 & 24.90 & 5.43 & 47.47 \\
\hline 5 & 1.45 & 3.93 & 28.83 & 4.30 & 51.77 \\
\hline 6 & 1.33 & 3.61 & 32.44 & 3.61 & 55.38 \\
\hline 7 & 1.26 & 3.41 & 35.85 & 3.23 & 58.61 \\
\hline 8 & 1.23 & 3.31 & 39.16 & 3.04 & 61.65 \\
\hline 9 & 1.14 & 3.09 & 42.25 & 2.64 & 64.29 \\
\hline 10 & 1.12 & 3.02 & 45.27 & 2.51 & 66.80 \\
\hline 11 & 1.09 & 2.94 & 48.21 & 2.39 & 69.19 \\
\hline 12 & 1.04 & 2.80 & 51.01 & 2.17 & 71.36 \\
\hline 13 & 1.02 & 2.76 & 53.77 & 2.10 & 73.46 \\
\hline 14 & 1.01 & 2.73 & 56.50 & 2.06 & 75.52 \\
\hline 15 & 0.98 & 2.66 & 59.16 & 1.94 & 77.46 \\
\hline 16 & 0.97 & 2.62 & 61.77 & 1.89 & 79.35 \\
\hline 17 & 0.93 & 2.51 & 64.28 & 1.73 & 81.08 \\
\hline 18 & 0.91 & 2.47 & 66.75 & 1.68 & 82.76 \\
\hline 19 & 0.91 & 2.45 & 69.20 & 1.65 & 84.41 \\
\hline 20 & 0.90 & 2.44 & 71.64 & 1.64 & 86.05 \\
\hline 21 & 0.86 & 2.34 & 73.98 & 1.50 & 87.55 \\
\hline 22 & 0.85 & 2.29 & 76.27 & 1.43 & 88.98 \\
\hline 23 & 0.81 & 2.20 & 78.47 & 1.33 & 90.31 \\
\hline 24 & 0.80 & 2.17 & 80.64 & 1.29 & 91.60 \\
\hline 25 & 0.77 & 2.08 & 82.72 & 1.18 & 92.78 \\
\hline 26 & 0.72 & 1.95 & 84.67 & 1.03 & 93.81 \\
\hline 27 & 0.71 & 1.92 & 86.59 & 1.00 & 94.81 \\
\hline 28 & 0.71 & 1.91 & 88.50 & 0.99 & 95.80 \\
\hline
\end{tabular}




\begin{tabular}{|l|l|l|l|l|l|}
\hline 29 & 0.65 & 1.76 & 90.26 & 0.84 & 96.64 \\
\hline 30 & 0.59 & 1.60 & 91.86 & 0.69 & 97.33 \\
\hline 31 & 0.55 & 1.49 & 93.35 & 0.60 & 97.93 \\
\hline 32 & 0.55 & 1.49 & 94.84 & 0.59 & 98.52 \\
\hline 33 & 0.50 & 1.34 & 96.18 & 0.48 & 99.00 \\
\hline 34 & 0.43 & 1.17 & 97.34 & 0.36 & 99.36 \\
\hline 35 & 0.40 & 1.09 & 98.44 & 0.31 & 99.67 \\
\hline 36 & 0.39 & 1.04 & 99.48 & 0.28 & 99.95 \\
\hline 37 & 0.19 & 0.52 & 100.00 & 0.07 & 100.00 \\
\hline
\end{tabular}

NOTE: THE fIRST TWO FACTORS SUMMARIZE 15.5 PERCENT OF THE TOTAL VARIANCE, AND 35.21 PERCENT WHEN USINg THE MODIfIED RATE.

Figure A1 - Cloud of individuals of the unstandardized factor analysis of the Indian social space. Plane 1-2

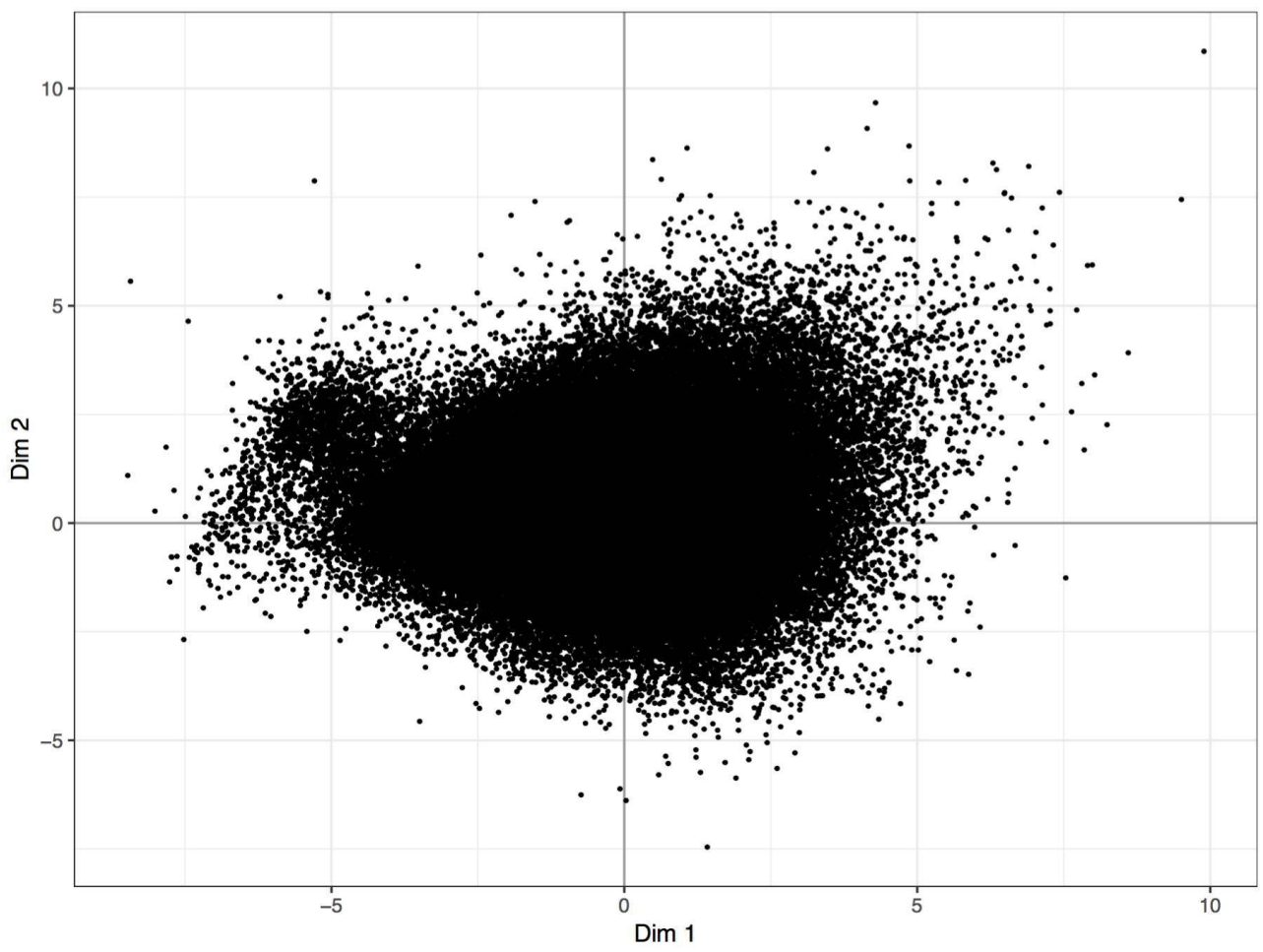

71 The first results on the two selected axes immediately reveal the importance of the geographic location of the households (although this tendency had already been taken into consideration in our choice of variables). The "States" variable is the most highly correlated, by far, not only on the second axis but also on the following axes, while on axis 1 it is already in second position after the level of consumption. In other words, 
although it is not the first, the State variable "explains" a large share of the correlations observed.

This regional dimension of our results tends to mask other social disparities in the social space (see the core article, part II, on this point). These potentially hidden associations are unfortunately those we were initially trying to objectify when we started our project. We hence run a Standardized Factor Analysis (SFA, see Bry, Robette and Roueff, 2015 for a complete description) to neutralize geographical variations in the representation of the social space. The SFA consists of integrating a reasoning of the type: "all other things being equal" based on regression analyses, into the context of a factor analysis. A first factor analysis is performed (in our case it corresponds to the PCA presented above) and the coordinates of the people on each axis selected for the rest of the analysis are extracted. Then a series of linear regressions is carried out (as many as there are axes selected, in our case ten) using the people's coordinates as dependent variables and the variable(s) to be "neutralized" as (an) independent variable(s). The residues of each regression are collected to obtain a table of coordinates of individuals on each selected axis "free" of the effects of the "neutralized" variables (see table A1, A2 and A3). A principal component analysis based on these new coordinates then makes it possible to obtain a new factor space, on to which the active variables from the initial analysis are projected as supplementary variables.

Applying SFA to the geometric plane also makes it impossible to use statistics that are traditionally mobilized in order to assess the contribution of each factor to the dispersion of individuals (variance of axes and contribution of individuals and categories to the axes). The analysis hence focuses on the levels of correlation of the active variables to the axes, which corresponds to the graphic coordinates of the variables. In addition, this measurement is completed by the quality of the representation of the active variables on the axes $\left(\cos ^{2}\right.$ measurements, see Table A1). In what concerns the supplementary variables, we use the v-test, which measures the distance (expressed in standard deviations of the normal distribution) between the modalities and the center of the axis. The higher the value, the better the modality characterizes the axis. Above all, the graphic interpretation is exploited (see Figure A2 and Figure A3). The active variables close to the origin of both axes (below 0.01) are not essential to the construction of the geometrical plane, and hence we do not project them on the figure. With regard to the supplementary social position variables, we represent the modalities with test values that are among the thirty highest on at least one of the axes. It should be noted that for the social position variables (and only for these), the variables close to the origin of the axes are not eliminated, as we consider these variables important for an attempt to understand the "middle" of the social space. Lastly, the analysis is attentive to the "eta" indices which measure the structuring power of the supplementary variables on an axis (this index calculates the relationship between the variance of the modalities of a variable and the variance of an axis). 
Figure A2 - Unstandardized factor analysis of the Indian social space. Plane 1-2

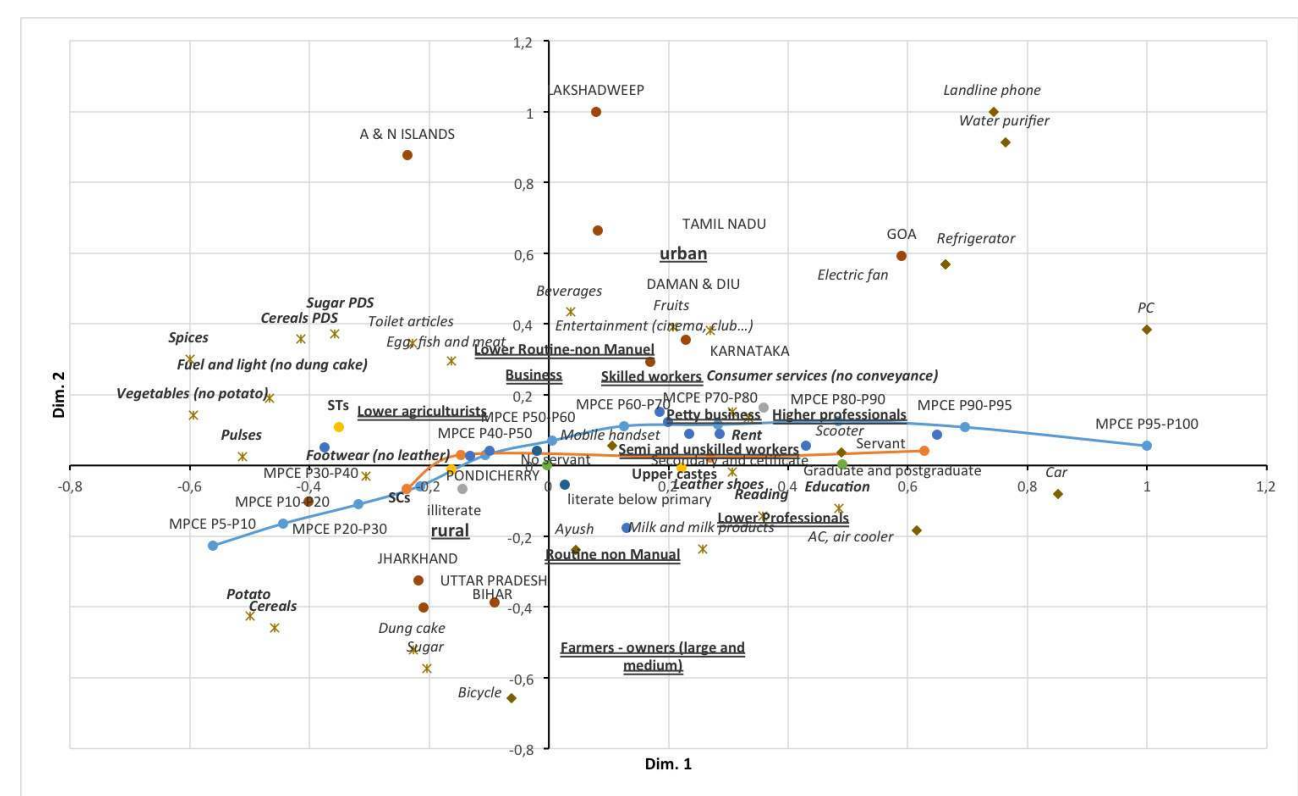

NOTE: IN BLUE: CONSUMPTION LEVEL, OTHER DOTS: OTHER POSITION VARIABLES, CROSSES: THE SHARE OF THE BUDGET DEDICATED TO EACH GOOD; DIAMONDS: EXPENDITURE LEVEL FOR EACH GOOD OWNED.

74 If our SFA is based on ten factors, our analysis is nonetheless limited to its first two factors. This is why, in order to attain more robust results, we finally decided to also run an Ascending Hierarchical Classification (AHC) on the first ten factors of the SFA. As presented in the core of the article (part III, section 2), this allows to push further the multidimensional approach of the Indian social space by simultaneously integrating in the analysis elements that could not be combined when interpreting the first two axes of the SFA. It is to be noticed here that the results of the AHC conducted on the ten axes are similar (although not identical) to the classification results obtained when limiting ourselves to the first two or three factors of the SFA. This comforts our analysis: the first two factors summarize adequately the variability of the household budget. 
Figure A3 - Cloud of individuals of the standardized factor analysis of the Indian social space. Plane 1-2

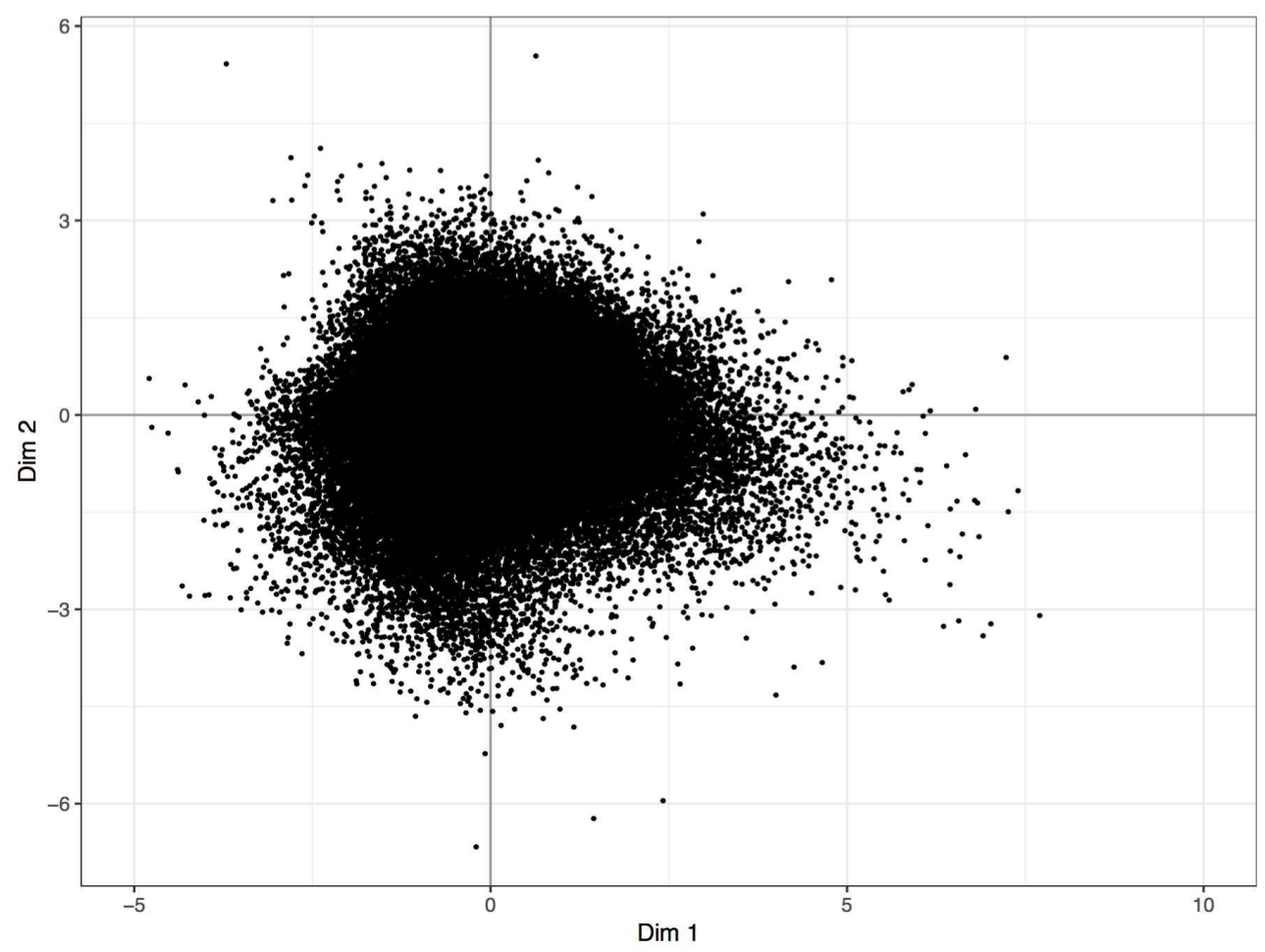

\section{Appendix 2: Zooms on the social space}

The replication of our study on different sub-samples of the NSS "consumption" survey reveals both a global stability of the results found at the all-India level as well as some minor-but heuristic-variations. It also confirms the accuracy of a relational analysis that takes into account all available social properties rather than monetary wealth only. This appendix presents these results, based on the production of standardized factor analyses (see Appendix 1) for two sets of subsamples: the urban and the rural households, and the richest, intermediate, and poorest households.

\section{Variations according to the rural/urban continuum: more capital in cities}

76 As mentioned in the article, the urban is commonly associated with the megapolis and the rural with the small isolated, agricultural village. Common sense hence tends to position them as two incommensurable universes. To explore further this rural/urban divide, we created two subpopulations, one urban (Figure B1) and the other rural (Figure B2), in order to produce two separate SFAs (or standardized PCAs). 
Figure B1 - Standardized factor analysis, close-up of urban areas. Plane 1-2

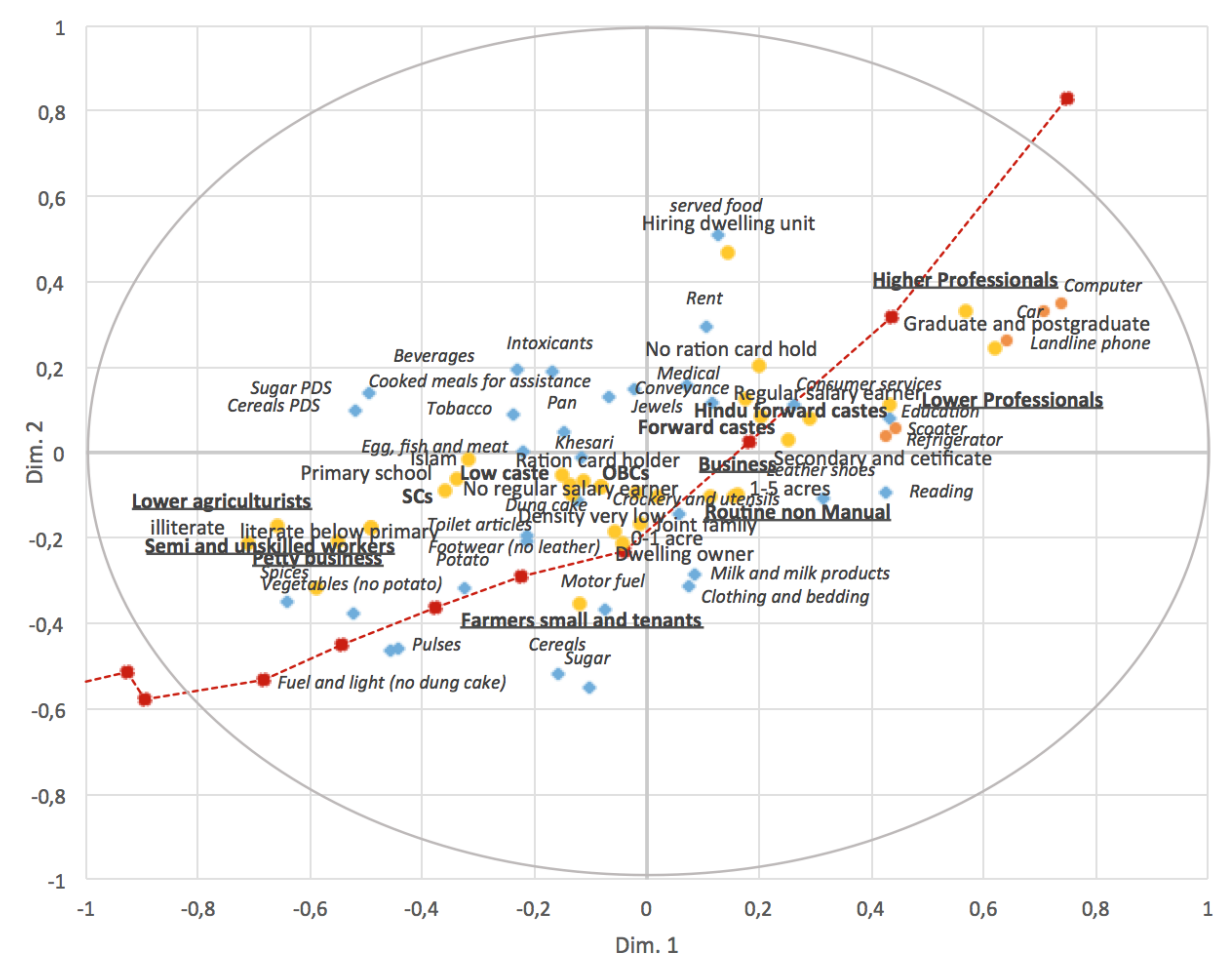

NOTE: IN RED, THE CONSUMPTION LEVEL; YELLOW DOTS: THE OTHER POSITION VARIABLES

(SPECIfICALLY: LEVEL OF EDUCATION, PROFESSIONAL CATEgORY, RELIgION, SCHEDULED CASTE, DEMOgRAPHIC DENSITY, LAND OWNERSHIP, AREA OF RESIDENCE); IN BLUE: PROPORTION OF THE BUDGET DEDICATED TO EACH GOOD; ORANGE DOTS: THE LEVEL OF EXPENDITURE FOR EACH GOOD.

DATA: CONSUMER EXPENDITURE SURVEY, NATIONAL SAMPLE SURVEY 68TH ROUND (2011-2012) 
Figure B2 - Standardized factor analysis, close-up of rural areas. Plane 1-2

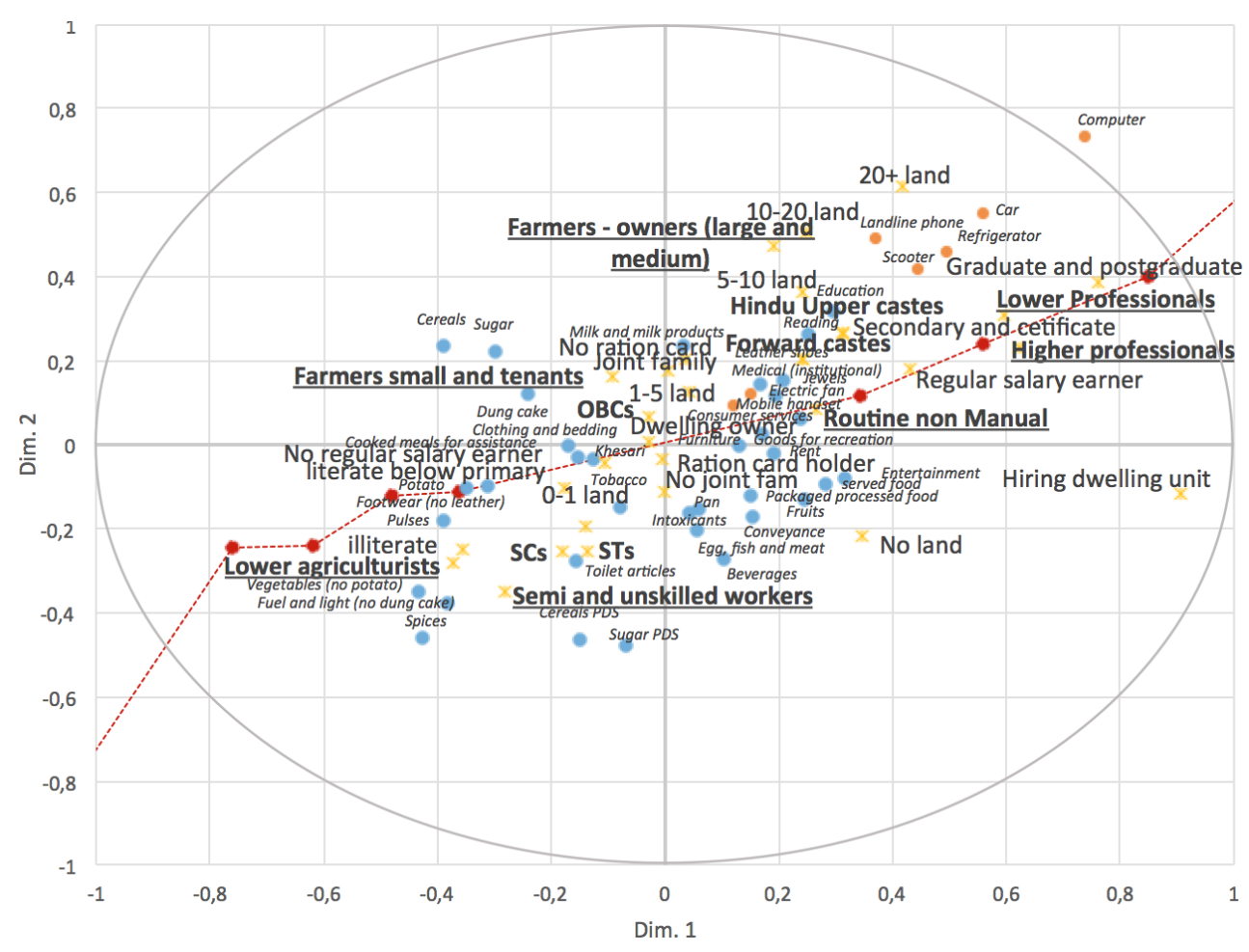

NOTE: IN RED, THE CONSUMPTION LEVEL; YELLOW DOTS: THE OTHER POSITION VARIABLES (SPECIficAlly: LEVEL Of EDUCATION, PROFESSIONAL CATEgORY, RELIgION, SCHEDULED CASTE, DEMOgRAPHIC DENSITY, LAND OWNERSHIP, AREA OF RESIDENCE); IN BLUE: PROPORTION OF THE BUDGET DEDICATED TO EACH gOOD; ORANGE DOTS: THE LEVEL OF EXPENDITURE FOR EACH gOOD.

DATA: CONSUMER EXPENDITURE SURVEY, NATIONAL SAMPLE SURVEY 68TH ROUND (2011-2012)

77 To start with, the two spaces are overall very similar to each other and to the global space. The first impression is that we are dealing with a copy of the global SFA. Indeed one notices the same diagonal that contrasts the rich, educated and professionals, with the poor, little educated and subaltern workers, and the possession of comfort goods with the share of expenditure on subsistence goods. It is only by carefully observing the contributions of the position variables to axes 1 and 2 that one can see some minor differences (Table B1).

Table B1 - Rural and Urban SFA: correlations of supplementary variables to axes 1 and 2

\begin{tabular}{|c|l|c|c|c|c|}
\hline \multicolumn{2}{|c|}{} & \multicolumn{2}{c|}{ Urban } & \multicolumn{2}{c|}{ Rural } \\
\hline \multirow{2}{|c|}{} & & Axe 1 & Axe 2 & Axe 1 & Axe 2 \\
\hline Eta $^{2}$ & Rural/Urban & - & - & - & - \\
\cline { 2 - 6 } & MPCE & $32 \%$ & $19 \%$ & $30 \%$ & $7 \%$ \\
\cline { 2 - 6 } & Social position & $16 \%$ & $3 \%$ & $10 \%$ & $7 \%$ \\
\cline { 2 - 7 }
\end{tabular}




\begin{tabular}{|l|c|c|c|c|}
\hline Land owning & $1 \%$ & $7 \%$ & $3 \%$ & $5 \%$ \\
\hline Education level & $24 \%$ & $2 \%$ & $12 \%$ & $4 \%$ \\
\hline Caste & $4 \%$ & $0 \%$ & $3 \%$ & $3 \%$ \\
\hline Joint family & $0 \%$ & $1 \%$ & $0 \%$ & $2 \%$ \\
\hline Hindu or non-Hindu castes & $4 \%$ & $0 \%$ & $3 \%$ & $2 \%$ \\
\hline Salaried worker & $3 \%$ & $1 \%$ & $5 \%$ & $1 \%$ \\
\hline Ration card & $2 \%$ & $1 \%$ & $0 \%$ & $1 \%$ \\
\hline Religion & $2 \%$ & $0 \%$ & $0 \%$ & $0 \%$ \\
\hline Servant & $0 \%$ & $0 \%$ & $0 \%$ & $0 \%$ \\
\hline Density & $0 \%$ & $2 \%$ & $0 \%$ & $0 \%$ \\
\hline Residential status & $1 \%$ & $8 \%$ & $3 \%$ & $0 \%$ \\
\hline
\end{tabular}

Note: Eta ${ }^{2}$ measures the correlation between the axis and the categorical variables. MPCE "explains" 32 percent of the variance of axis 1 in urban areas, 30 percent in rural areas.

\section{DATA: CONSUMER EXPENDITURE SURVEY, NATIONAL SAMPLE SURVEY 68TH ROUND} (2011-2012)

In urban areas, the relationship to ownership of the residence and land is associated with axis 2, connected to demographic density: there is an opposition between small landowners and people who own their homes on the one side and non-landowners and people who rent their homes on the other side. Counter intuitively, in comparison to other countries, it is the fact of being an (small) owner that correlates with low levels of consumption and education, and the fact of being a tenant of one's residence that is associated with high levels of expenditure and education. This does not signify that the majority of poor people own their homes, but rather, it expresses differential relationships to the contractualization of economic relationships. Often, a corner of a property or a building is "made available" to the families of those employed by the owner (or one of his allies), or these spaces are informally rented (without a lease, rent receipts, etc.), or makeshift housing is tolerated in an area of a commune of uncertain ownership... Thus, while most poor people's status in terms of their residence would, in some way, be "tenant" or "usufructuary", these legal categories are, in fact, incorrect and do not make sense to the people concerned (some, who built their accommodation themselves, may even consider themselves the "owners" of it). Only the richest, less socially distanced from their owner when they are tenants, declare themselves to be "tenants" (and they more often draw up contracts). As for small landowners, they are located on the side of low demographic densities on axis 2 and among the high levels of consumption on axis 1 : the richest owners of their homes, which also have land attached to them, live in residential areas.

Inversely, in rural areas, the occupancy status of the home, and ownership of land are not associated to the same axis. When we find tenants on the "rich" side, they are associated 
with axis 1 . On axis 2 , small owners shift to the "poor" side and the modalities of large owners appear on the "rich" side, associated with farmer owners. The second axis thus contrasts households that have land capital with industrial or agricultural worker households that possess no capital other than their labor power and, sometimes, a small farm-in short the axis contrasts capitalists with their employees. The former are also (weakly) associated with OBCs, which include a certain number of castes that are dominant in rural areas, and the latter with SCs and STs, although they are little differentiated on axis 1 . Axis 1, for its part, contrasts levels of consumption and education, such as those associated or not with a qualified salaried job (this is why lower professionals are found on the side of the professionals).

Thus, in rural and urban areas, the contrasting principles are very similar with, nonetheless, slight secondary differences. The social structure is globally the same but tempered by the specificities of urban and rural spaces. This is confirmed by the distribution of professional categories, levels of consumption and levels of education, depending on whether the person lives in a rural or urban area (see tables B2, B3 and B4). Unsurprisingly this distribution reproduces the polarization visible in the global SFA, but additionally it appears to be strictly linear. The higher is the urban share, the higher the level of expenditure, the level of education and the professional category (with the expected exception of farmers who own large and average size farms).

Table B2 - Social position by sector of residence

NOTE: 25 PERCENT OF HIgHER PROFESSIONALS LIVE IN RURAL AREAS. 


\begin{tabular}{|l|l|l|l|}
\hline & Rural & Urban & Total \\
\hline Higher professionals & 25.0 & 75.0 & 100 \\
\hline Lower Professionals & 46.9 & 53.1 & 100 \\
\hline Routine non Manual & 45.6 & 54.4 & 100 \\
\hline Lower Routine-non Manuel & 47.5 & 52.5 & 100 \\
\hline Business & 42.3 & 57.7 & 100 \\
\hline Petty business & 56.1 & 43.9 & 100 \\
\hline Skilled workers & 45.4 & 54.6 & 100 \\
\hline Semi and unskilled workers & 67.1 & 32.9 & 100 \\
\hline Farmers-owners (large and medium) & 94.6 & 5.4 & 100 \\
\hline Farmers small and tenants & 97.1 & 2.9 & 100 \\
\hline Lower agriculturists & 95.9 & 4.1 & 100 \\
\hline Total & 71.4 & 28.6 & 100 \\
\hline
\end{tabular}

DATA: CONSUMER EXPENDITURE SURVEY, NATIONAL SAMPLE SURVEY 68TH ROUND (2011-2012)

\section{Table B3 - Level of consumption by sector of residence}

NOTE: 94.1 PERCENT OF THE POPULATION BELONgINg TO THE 5 PERCENT FRACTILE OF THE LOWEST LEVEL OF CONSUMPTION LIVE IN RURAL AREAS.

\begin{tabular}{|l|l|l|l|}
\hline & Rural & Urban & Total \\
\hline MPCE P0-P5 & 94.1 & 5.9 & 100 \\
\hline MPCE P5-P10 & 91.1 & 8.9 & 100 \\
\hline MPCE P10-P20 & 88.9 & 11.1 & 100 \\
\hline MPCE P20-P30 & 87.2 & 12.8 & 100 \\
\hline MPCE P30-P40 & $84 ; 5$ & 15.5 & 100 \\
\hline MPCE P40-P50 & 79.2 & 20.8 & 100 \\
\hline MPCE P50-P60 & 76.9 & 23.1 & 100 \\
\hline MPCE P60-P70 & 69.7 & 30.3 & 100 \\
\hline
\end{tabular}




\begin{tabular}{|l|l|l|l|}
\hline MCPE P70-P80 & 60.1 & 39.9 & 100 \\
\hline MPCE P80-P90 & 47.1 & 52.9 & 100 \\
\hline MPCE P90-P95 & 34.2 & 65.8 & 100 \\
\hline MPCE P95-P100 & 22.0 & 78.0 & 100 \\
\hline Total & 71.4 & 2.6 & 100 \\
\hline
\end{tabular}

DATA: CONSUMER EXPENDITURE SURVEY, NATIONAL SAMPLE SURVEY 68TH ROUND (2011-2012)

\section{Table B4 - Level of education by sector of residence}

NOTE: 84.7 PERCENT OF THE POPULATION THAT LIVES IN A HOUSEHOLD IN WHICH THE REFERENCE PERSON IS ILLITERATE, LIVES IN A RURAL AREA.

\begin{tabular}{|l|l|l|l|}
\hline & Rural & Urban & Total \\
\hline Illiterate & 84.7 & 15.3 & 100 \\
\hline Literate below primary & 79.1 & 20.9 & 100 \\
\hline Primary school & 75.1 & 24.9 & 100 \\
\hline Middle school & 71.8 & 28.2 & 100 \\
\hline Secondary and certificate & 56.6 & 43.4 & 100 \\
\hline Graduate and postgraduate & 32.2 & 67.8 & 100 \\
\hline Total & 71.4 & 28.6 & 100 \\
\hline
\end{tabular}

DATA: CONSUMER EXPENDITURE SURVEY. NATIONAL SAMPLE SURVEY, 68TH ROUND (2011-2012)

\section{Variations according to the wealth (MPCE) continuum: a scale with many levels}

81 Zooming on various subsamples in terms of wealth produces similar results as zooming on the rural and urban sub-spaces. Whether it is for the 20 percent richest households, the 50 percent intermediate households, or the 30 percent poorest households, results are very similar, displaying only minor but heuristic differences.

Is the "middle class" made up of the richest 20 percent?

82 The first lesson taught by zooming on the richest 20 percent subsample of our population (Figure B3), is that the Hindu and non-Hindu forward castes are associated with higher 
levels of capital. It also reveals that in this area of the Indian social space the Muslims and SCs are not only less endowed with capital, but also more often urban. This is certainly because, for these discriminated religious and caste minorities, the escape from dominant castes' power is more direct and enduring in rural areas, and the opportunities for social ascension by enrichment are more likely to exist in cities.

The second lesson is that while the graph is very similar to the overall SFA, the second axis is more obviously constructed around the urbanization rate. The main opposition it reveals is between the highest urban densities on the one side and the highest rural densities on the other side (with low urban densities and low rural densities closer to the origin of the axes). This is something that we do not find in the other spaces where the dispersion of densities on axis 2 is strictly linear. The lowest fractions of the affluent social space, are clearly associated with rural areas but they are nevertheless more urbanized than the rural fractions of the intermediate and popular social spaces. In other words, affluent classes are better described as distributed among different level of urbanization (from small cities to megapolis) rather than as split between rural and urban areas. This is probably linked to the fact that it is very unlikely to be among the top 20 percent in terms of income and live in a rural, scarcely dense area.

The third lesson is that we clearly see that major differences contrast the upper class, who are also highly qualified, and higher professionals, with the other well-to-do people, who are sometimes little qualified such as semi and unskilled manual workers, or lower agriculturalists. In other words, some comfort goods (computer, refrigerator, car, etc.) are not accessible to the less rich of the richest 20 percent. The fact that the opposition between comfort goods and basic goods also constitutes, for the richest 20 percent, the main factor of polarization between styles of consumption, is an important indicator both of the strength of the structure of this opposition across the whole Indian social space, and of the considerable divergences that exist at the "apex" of this space.

It hence becomes difficult to identify the richest 20 percent with a homogeneous "middle class": it is not only extremely heterogeneous but also, for the most part, far removed from the stereotype of the mobile urban executive who frequents luxury boutiques in large shopping malls. 
Figure B3 - SFA, close-up of the richest 20 percent (deciles 80 to 100). Plane 1-2

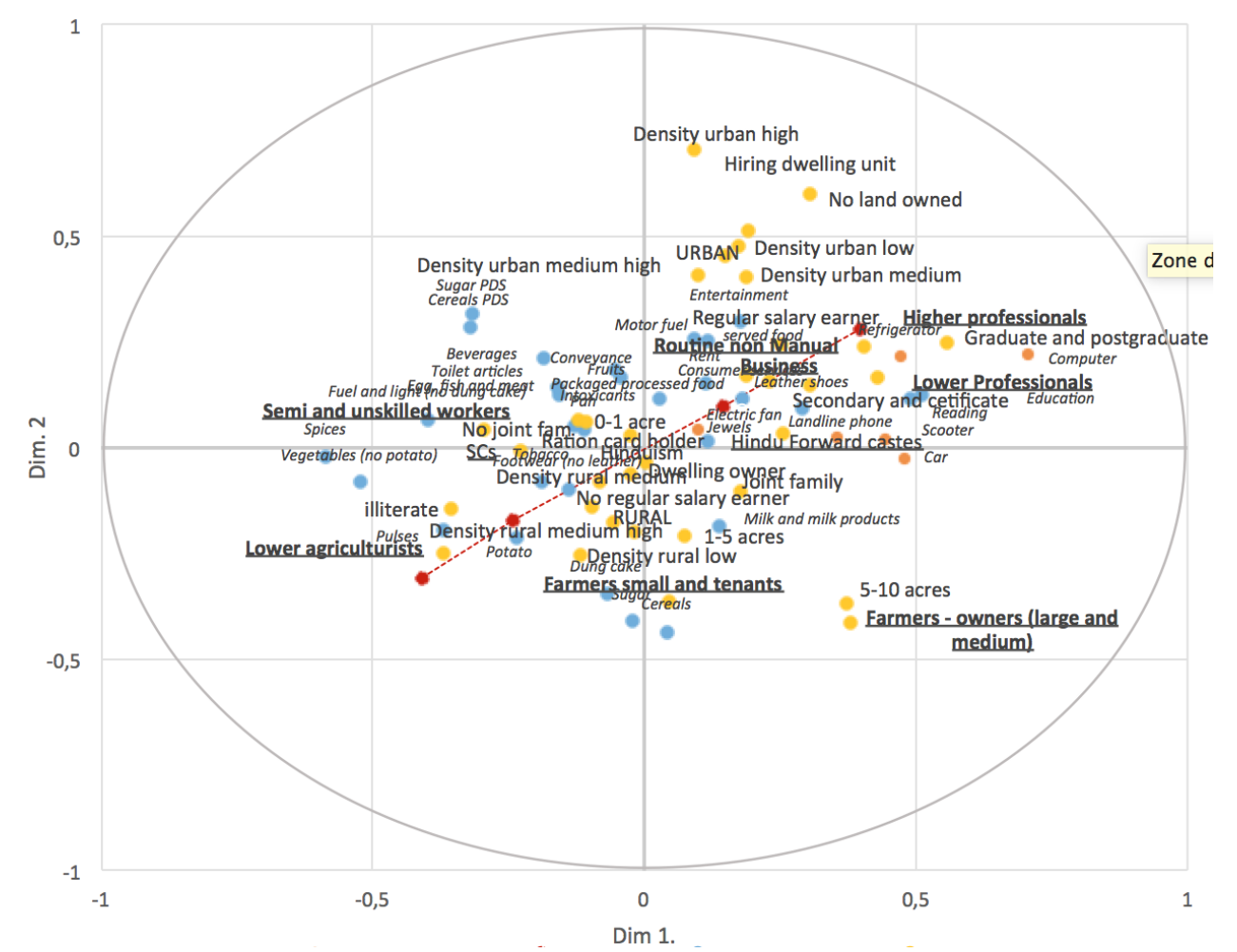

NOTE: IN RED, THE CONSUMPTION LEVEL; YELLOW DOTS: THE OTHER POSITION VARIABLES (SPECIfICALlY: LEVEL Of EDUCATION, PROFESSIONAL CATEgORY, RELIgION, SCHEDULED CASTE, DEMOgRAPHIC DENSITY, LAND OWNERSHIP, AREA OF RESIDENCE); IN BLUE: PROPORTION OF THE BUDgET DEDICATED TO EACH gOOD; ORANGE DOTS: THE LEVEL OF EXPENDITURE FOR EACH gOOD.

DATA: CONSUMER EXPENDITURE SURVEY, NATIONAL SAMPLE SURVEY 68TH ROUND (2011-2012)

\section{The "intermediate" 50 percent: the key resource of education}

In line with previous results, the analysis of the social space of the intermediate levels of consumption does not reveal significant differences with the results at the pan-Indian level (Figure B4).

The most interesting difference appears when one focuses on levels of education. Among the richest 20 percent there exists a division between the very highly qualified (graduates and postgraduates) and the others (including the middle school level). The distinguishing factor within a population that is overall qualified, is being highly qualified-or inversely, not having any qualification, hence the significance of all the "low education" modalities (illiterate, literate below primary and primary school, followed by middle school). In this sub-space, only three modalities are significantly different from the global space: there is a contrast between the illiterate on the one side and the (post)graduates, secondary and certificate levels on the other side. Here, it is the mere fact of having prolonged one's education that is distinctive and that draws the most educated towards the "top" of this intermediate zone.

At a wider level, this vast intermediate zone, made up of 50 percent of the population, does not really show any sociological traits that would distinguish it from the other spaces studies. 
Figure B4 - SFA, close-up of the intermediate 50 percent (deciles 40 to 80 ). Plane 1-2

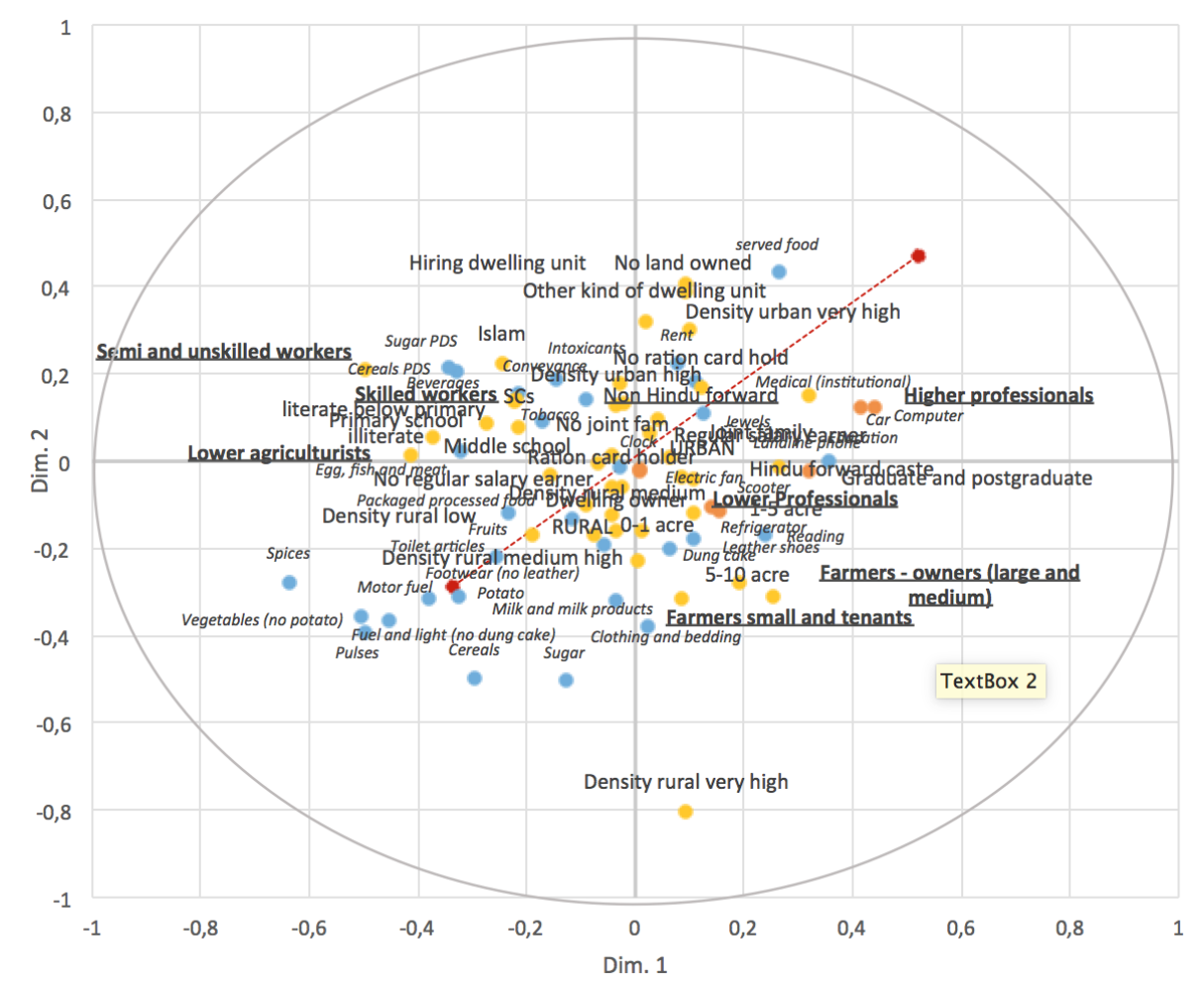

NOTE: IN RED, THE CONSUMPTION LEVEL; YELLOW DOTS: THE OTHER POSITION VARIABLES (SPECIfiCALLY: LEVEL OF EDUCATION, PROFESSIONAL CATEgORY, RELIgION, SCHEDULED CASTE, DEMOgRAPHIC DENSITY, LAND OWNERSHIP, AREA OF RESIDENCE); IN BLUE: PROPORTION OF THE BUDgET DEDICATED TO EACH GOOD; ORANGE DOTS: THE LEVEL OF EXPENDITURE FOR EACH GOOD. DATA: CONSUMER EXPENDITURE SURVEY, NATIONAL SAMPLE SURVEY 68TH ROUND (2011-2012)

The poorest 30 percent: the empire of need

By zooming in to take a closer look at the poorest 30 percent (Figure 5), we first note that the position variables projected as supplementary variables sometimes behave surprisingly. To start with, the routine non-manual workers are located on the left and all the other social class variables are on the right, with the professionals being close to the unskilled or semi-skilled workers (while qualified workers and agricultural workers are not contributing significantly to the construction of the axis). In a similar way, in terms of level of education, on the left of the axis, the illiterate are associated with the secondary level and certificate holders, while the primary school level and uncertified high school level are on the right, along with the graduates and postgraduates. The caste and religion variables are also related in a way that differs from what is observed on the other spaces (but that helps explain the inconstancies in terms of education noticed above). The opposition observed is indeed not one between forward groups and low-status groups but one between Hindus of relatively high status (forward Hindus and $\mathrm{OBC}$ ) and low castes and religious minorities (whether or not from forward caste). On the right, the Hindu forward castes are the furthest from the origin of axis 1, the OBCs are closer to the origin, and on the left we find the castes that are traditionally considered inferior (SCs) with the Muslim and Buddhist religious minorities (not far from the origin). The non-Hindu 
forward castes and the STs are both significant and located on the origin of axis 1, slightly to its left. It thus seems that among the poorest populations, the fact of belonging to a Hindu forward caste or to an "other backward class" distinguishes the person from all the other caste or religious minority attributes. In this sense one can interpret the apparent inconsistencies of the professional category and of the level of education as an indication that the small differences between the poor are more strongly based on caste than on education (rare) or on the social class (as anyway most of them are workers and agricultural workers). Among the populations that possess no economic or cultural capital, the caste one belongs to would hence make an enormous difference in terms of creating a minimum distance from the weight of need.

The subspace of the poorest reveals interesting other minor differences. If at first look one can observe a contrast between comfort goods and basic goods on axis 1 , as well as an opposition between goods of a more urban character and goods that are more common in rural areas on axis 2, this impression needs to be tempered. The zone of "rural" goods only contains the variable "cereals" while some goods that are, in other sub-spaces, located on the "rural" side are now located on the "urban" one. Pulses thus turn out to become "urban". In a similar fashion, "spices" are located on the "poor" side and sugar on the "rich" side of axis 1, a reversed location compared to what is observed on the other spaces and subspaces studied. What thus seems to be inconsistent cannot, in reality, better express the effect of need: what is considered poor people's goods for the intermediate classes becomes rich people's goods for the poorest. In other words, what constitutes a basic good at a certain level (and thus weighs strongly on the budget of the poorest) is considered a luxury lower down (and is thus traded-off from the consumption basket of the poorest of the poorest).

91 The third point is that this sub-space reveals what constitute the cumulative disadvantages that produce extreme deprivation. Indeed, the position variables, projected as supplementary variables, are all aligned on axis 1-which thus represents not only the level of wealth, but the volume of almost all economic, cultural, caste, professional resources. Even ownership of land and the fact of working as a farmerowner, which are more dispersed on the rural/urban axis (2) in other spaces and subspaces, are here mainly dispersed on axis 1 . Furthermore, the only position variable that makes a slightly significant contribution to axis 2 (4 percent of inertia) is the possession of a ration card. This means that this axis mainly expresses the relationship to state aid for the most disadvantaged, which we have already described as being more accessible in urban areas: at this level of the social space, getting access to state aid is not a sign of deprivation but rather a sign of integration. In summary, in the south of axis 2 , one finds the absence of ration card, Buddhism, very low urban density, and all of these variables are associated with the "cereals" variable, that is the most vital and essential food item. This is hence in the South of this subspace that are located the most dominated amongst the dominated. Their portrait is one of Dalits converted to Buddhism, who are excluded from accessing administrative resources (although these are intended for the poorest), who eat the most basic food and who live in areas devoid of both urban microopportunities as well as rural micro-resources (particularly home production). ${ }^{18}$ 
Figure B4 - SFA, close-up of the poorest 30 percent (deciles 0 to 30). Plane 1-2

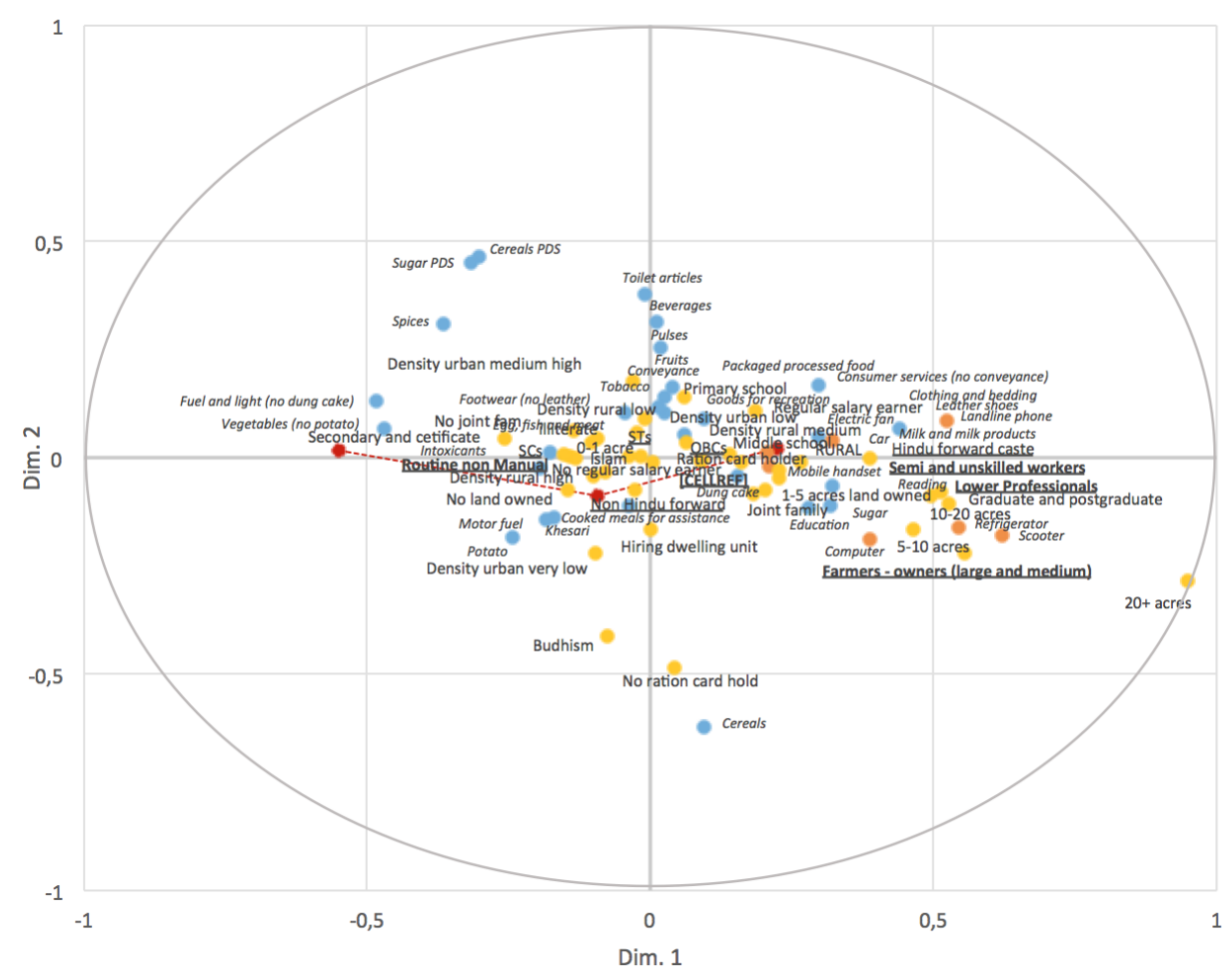

NOTE: IN RED, THE CONSUMPTION LEVEL; YELLOW DOTS: THE OTHER POSITION VARIABLES (SPECIfICALLY: LEVEL OF EDUCATION, PROFESSIONAL CATEgORY, RELIgION, SCHEDULED CASTE, DEMOgRAPHIC DENSITY, LAND OWNERSHIP, AREA OF RESIDENCE); IN BLUE: PROPORTION OF THE BUDGET DEDICATED TO EACH GOOD; ORANGE DOTS: THE LEVEL OF EXPENDITURE FOR EACH GOOD.

DATA: CONSUMER EXPENDITURE SURVEY, NATIONAL SAMPLE SURVEY 68TH ROUND (2011-2012)

In conclusion, these zooms confirm the relevance of taking into account the secondary differentiating factors that "complicate" the massive effect of the level of consumption. Beyond a division into two (a two-tier India) or three (the classic upper, middle and lower classes), it is more heuristic to produce a typology of the Indian social space that at the same times reveals the dizzying length of the social scale, its twists dependent on the combination of varying social power relationships (wealth, profession, education, caste) and the multiplicity of its successive levels. This typology is presented in the core article.

\section{BIBLIOGRAPHY}

Beinhocker, Eric D., Diana Farrell and Adil S. Zainulbhai. 2007. "Tracking the growth of India's middle class" The McKinsey Quarterly 3: 50-61.

Bennett, Tony, Michael Emmison and John Frow. 1999. Accounting for Tastes: Australian Everyday Cultures. Cambridge: Cambridge University Press 
Bennett, Tony, Mike Savage, Elizabeth Silva, Alan Warde, Modesto Gayo-Cal and David Wright. 2009. Culture, class, distinction, Routledge, London \& New York.

Borges Pereira, Virgilio. 2005. Classes e Culturas de Classe das Famílias Portuenses. Classes sociais e "modalidades de estilização da vida" na cidade do Porto. Porto: Afrontamento/Instituto de Sociologia da Faculdade de Letras da Universidade do Porto.

Brousse, Cécile. 2013. “Existe-t-il un espace social européen?”. Paper presented at the Congress of the Association Française de Sociologie. Nantes, September 2013

Bry, Xavier, Nicolas Robette and Olivier Roueff. 2015. “Adressing Structural Effects within a Geometric Data Analysis”. Quality and Quantity 50(3): 1009-1020.

Chaudhuri, Kausik, Friedrich Schneider and Sumana Chattopadhyay. 2006. "The size and development of the shadow economy: An empirical investigation from states of India". Journal of Development Economics. 80(2): 428-443.

Clémentin-Ojha, Catherine. 2014. “'India, that is Bharat...': One Country, Two Names”. South Asia Multidisciplinary Academic Journal [Online], 10 | 2014, uploaded on 25 December 2014, URL: http:// samaj.revues.org/3717; DOI: 10.4000/samaj.3717, [accessed on 10 June 2016].

Cveticanin, Predrag and Mihaela Popescu. 2011. "The art of making classes in Serbia: Another particular case of the possible". Poetics 39: 444-468.

Dang, Hai-Han H. and Peter F. Lanjouw. 2015. "Poverty Dynamics in India between 2004 and 2012. Insights From Longitudinal Analysis Using Synthetic Panel Data". Policy Research Working Paper 7270. World Bank.

Deaton, Angus. 2001. "Counting the World's Poor: Problems and Possible Solutions". The World Bank Observer Research Observer 16(2): 125-147.

Deaton, Angus. 2003. “Adjusted Indian Poverty Estimates for 1999-2000”. Economic and Political Weekly 38(4): 322-326.

Denis, Eric, Partha Mukhopadhyay and Marie-Hélène Zérah. 2012. "Subaltern urbanization in India". Economic and Political Weekly. 47(30): 52-62.

Desai, Sonalde. 2007. "Indian Middle Class". in Oxford Companion to Economics in India, edited by K. Basu. New Delhi: Oxford University Press.

Deshpande, Satish. 2006."Mapping the 'Middle': issues in the analysis of the 'Non Poor' classes in India”. Pp. 215-236 in Contested Transformations: Changing Economies and Identities in Contemporary India, edited by M. John, P. K Jha and S. S. Jodhka. New Delhi: Tulika.

Driver, Edwin D. and Aloo E. Driver. 1987. Social class in urban India: essays on cognitions and structures. Leiden: E.J. Brill.

Dumont, Louis.1964. La Civilisation indienne et nous. Paris: Armand Colin.

Dupont, Véronique. 2013. "Which Place for the Homeless in Delhi? Scrutiny of a Mobilization Campaign in the 2010 Commonwealth Games Context". South Asia Multidisciplinary Academic Journal [Online] 8, Online since 17 December 2013, URL: http://samaj.revues.org/3662, [accessed on 11 June 2015].

Fernandes, Leela. 2006. India's New Middle Class. Democratic Politics in an Era of Economic Reform. Minneapolis and London: University of Minnesota Press.

Harriss-White, Barbara. 2003. India Working. Essays on Society and Economy. Cambridge: Cambridge University Press. 
Harriss-White, Barbara. 2004. “India's Informal Economy: Facing the $21^{\text {st }}$ Century”. Pp. 265-292 in India's Emerging Economy, edited by K. Basu, New Delhi: Oxford University Press.

Himanshu. 2015. “Inequality in India”. Seminar 672, http://www.indiaseminar.com/2015/672/672_himanshu.htm.

Hugrée, Cédric, Etienne Penissat and Alexis Spire. 2017. "Les déterminants sociaux et nationaux des inégalités culturelles en Europe”, Actes de la Recherche en Sciences Sociales, forthcoming.

Husson, François, Sébastien Lê and Jérôme Pagès. 2010. Analyse de données avec R. Rennes: PUR. Jaffrelot, Christophe. 2003. India's Silent Revolution. The Rise of the Lower Castes in North India. New York: Columbia University Press, London: Hurst, New Delhi: Permanent Black.

Jodhka, Surinder S. 2014. "Changing Face of Rural India", Economic and Political Weekly 49(14), 5 April 2014.

Jodhka, Surinder S. and Adarsh Kumar. 2017. "Non-farm Economy in Madhubani, Bihar: Social Dynamics and Exclusionary Rural Transformations”, Economic and Political Weekly, 52 (25-26), 24 June 2017

Jodhka, Surinder S. and Aseem Prakash. 2016. The Indian Middle Class. Delhi: Oxford University Press.

Joshi, Vijay. 2010. “Economic Resurgence, Lopsided Reform and Jobless Growth”. Pp. 73-106 in Diversity and Change in Modern India, edited by A. F. Heath, R. Jeffrey, Oxford: Oxford University Press.

Khilnani, Sunil. 2003. The Idea of India. Penguin UK: London.

Kumar, Sanjay, Anthony Heath and Oliver Heath. 2002. "Determinants of Social Mobility in India”. Economic and Political Weekly XXXVII(29), 20 July 2002: 2983-2987.

Lardinois, Roland.2013. Scholars and Prophets. Sociology of India from France. $19^{\text {th }}-20^{\text {th }}$ centuries. New Delhi: Social Science Press.

Le Roux, Brigitte and Henri Rouanet. 2004. Geometric Data Analysis: From Correspondence Analysis to Structured Data Analysis. Dordrecht: Kluwer Academic Publishers.

Le Roux, Brigitte and Henri Rouanet. 2005. Geometric data analysis: from correspondence analysis to structured data analysis. New York: Springer

Le Roux, Brigitte and Henri Rouanet. 2010. Multiple correspondence analysis. Thousand Oaks: Sage.

Maitra, Sudeshna. 2008. "Who are the Indian Middle Class A Mixture Model of Class Membership Based on Durables Ownership”. Working paper. York University (Toronto).

Mazzarella, William. 2005. "Middle Class", in Keywords in South Asian Studies, edited R. Dwyer, an online encyclopedia maintained by SOAS (https://www.soas.ac.uk/south-asia-institute/ keywords).

Meyer, Christian and Nancy Birdsall. 2012. “New Estimates of India's Middle Class: A Technical Note”. Washington D.C.: Center for Global Development.

Naudet, Jules and Claire-Lise Dubost. 2016. "The Indian exception: the densification of the network of corporate interlocks and the specificities of the Indian business system (2000-2012)". Socio-Economic Review, first published online January 26, 2016 doi:10.1093/ser/mwv035

Naudet, Jules. 2012. Entrer dans l'élite: Parcours de réussite en France, aux Etats-Unis et en Inde. Paris: Presses Universitaires de France. 
Rangarajan, C. and S. Mahendra Dev. 2014. "Counting the poor: measurement and other issues". Working paper. Mumbai: Indira Gandhi Institute of Development Research.

Rosenlund, Lennart. 2000. "Cultural change in Norway: cultural and economic dimensions". International Journal of Contemporary Sociology. 37(2): 245-275

Schiff, Maurice. 1994. "The Impact of Two-Tier Producer and Consumer Food Pricing in India". World Bank Economic Review 8 (1): 103-125.

Sharda, Bam Dev. 1977. Status Attainment in Rural India. Delhi: Ajanta Publications.

Shukla, Rajesh and Roopa Purushothaman. 2008. "Market Information Survey". New Delhi: National Council for Applied Economics Research.

Sinha, Aseema. 2015. "Scaling Up: Beyond the Subnational Comparative Method for India", Studies in Indian Politics 3(1): 128-133.

Sridharan, Eswaran. 2004. "The Growth and Sectoral Composition of India's Middle Class: Its Impact on the Politics of Economic Liberalization”. India Review. 3(4): 405-428.

Stepan, Alfred, Juan J. Linz and Yogendra Yadav. 2010. "The Rise of 'State-Nations'“, Journal of Democracy 21(3): 50-68.

Thorat, Sukhdeo and Joel Lee. 2005. "Caste Discrimination and Food Security Programmes", Economic and Political Weekly 40(39): 4198-4201.

Vaid, Divya and Anthony Heath. 2010. "Unequal Opportunities: Class, Caste and Social Mobility", in Diversity and Change in Modern India: Economic, Social and Political Approaches, edited by A. Heath and R. Jeffery. Oxford: Oxford University Press.

Vaid, Divya. 2012. "The Caste-Class association in India: an empirical analysis". Asian Survey. 52 (2): 395-422.

Varma, Pavan K. 1998. The Great Indian Middle Class. New Delhi: Penguin.

\section{NOTES}

1. We indeed postulate the existence of a unified Indian space as a working hypothesis that facilitates the study of the social structure of the Indian population. Though our article does not pretend to solve the complex issue of knowing whether or not there actually exists a unified social space, we nonetheless posit that analyzing data drawing upon such an assumption is actually heuristic.

2. We are aware that doing so does not constitute a definite proof of the unity of the Indian social space. This is not the aim of this paper.

3. On the application of these statistical techniques to different countries, see Bennett, Emmison and Frow (1999); Rosenlund (2000); Borges Pereira (2005); Bennett, Savage, Silva, Warde, Gayo-Cal and Wright (2009); Cveticanin and Popescu (2011).

4. For different definitions, all based on economic resources, see: Shukla and Purushothaman (2008);Beinhocker, Farrell and Zainulbhai (2007); Meyer and Birdsall (2012); Maitra (2007).

5. We refer the reader to the following works for further details on these methods of analysis: Le Roux and Rouanet (2010); Le Roux and Rouanet (2005); Husson, Lê and Pagès (2010).

6. Aggregated items are items that club together families of goods. This choice was particularly driven by an attempt to reduce the consumption variability between geographical zones (for example, vegetable oils were grouped together, to avoid a polarization between coconut oil and South Indian states, and mustard oil and Eastern states). 
7. We use States as a variable in our analysis (India is administratively a Federal State made up of 29 region States and 7 Union Territories, though there were only 28 States when the 2011-2012 NSS survey was conducted as Telangana had not been created yet).

8. Based on the decrease of eigenvalues we decide to interpret the first two axes. The contribution of axis 1 to the total inertia of the factorial cloud is 9.25percent and the contribution of axis 2 is 6.29 percent (cumulative variance is 15.54 percent). As suggested by Benzécri (Le Roux and Rouanet, 2004: 200), the modified rates allow for a better appreciation of the relative importance of the first axis. These are of 24.10percent for axis 1 and 11.11percent for axis 2 (see Appendix 1 for more details).

9. Before taking this decision, three ACPs were run on the subpopulations of Bihar, Kerala, and West Bengal in order to make sure that the main global structure was confirmed at the level of these three very contrasted States. Though there were some minor variations, the general results were very similar across the three States.

10. Dried "cow dung cakes" that are burnt as a source of energy for heating, or mainly for cooking: they are cheap and widespread in rural areas, particularly among farmers (cattle breeders).

11. "PDS": public distribution system. Access to subsidized goods is easier and hence more frequent among those entitled to them, in towns were public administrations are far more present and close, both in terms of geographical distance and mediation through personal networks (Thorat and Lee 2015).

12. Appendix 2 also provides further illustrations of the fact that these supplementary variables are not linear and redundant.

13. The constraint of a two-dimensional drawing unfortunately makes it impossible to take this information into account in Figure 4.

14. In their study of the non-farm economy in Madhubani, Surinder Jodhka and Adarsh Kumar (2017) have also shown the importance played by micro-resources in stratification processes at the bottom of society.

15. This was particularly driven by an attempt to reduce the consumption variability between geographical zones (for example, vegetable oils were grouped together, to avoid a polarization between coconut oil and South Indian states, and mustard oil and Eastern states).

16. The State variable is available here (we remind the reader that India is administratively a Federal State made up of 29 region States and Union Territories).

17. It should be noted that the ownership of goods variables were selected as supplementary variables so that they were not redundant with the budget variables.

18. A recent study of the dynamics of entering and exiting poverty clearly shows how much "small" resources determine highly contrasting probabilities of upward or downward reclassification (Dang and Lanjouw, 2015).

\section{ABSTRACTS}

This article takes as its specific starting point the idea that the Indian society constitutes a relational space, marked by the interdependency of various sub-spaces. It more precisely aims at producing a synthetic representation of the Indian social space. In order to do so, we draw upon the 2011-2012 data from the "Household Consumer Expenditure" survey of the National Sample 
Survey Office. The analysis leads us to produce a multidimensional typology of consumption and position profiles around which the households who make up the Indian social space are aggregated. Finally, we propose a summary figure of the principles that organize the Indian social space and the nine categories that comprise it. In the conclusion of the article, we discuss how this multidimensional approach to Indian society encourages to question prenotions like those of "middle class", "two-tier India", "urban-rural cleavage", or ideas drawn from politicobureaucratic language like "poverty threshold".

INDEX

Keywords: relational space, social space, multidimensional social stratification, factor analysis, social class, caste, urban-rural, poverty threshold

\section{AUTHORS}

\section{MATHIEU FERRY}

OSC \& LSQ (GENES-CREST), Paris

\section{JULES NAUDET}

Centre for South Asian Studies (CEIAS), EHESS, Paris

OLIVIER ROUEFF

CRESPPA, Paris 